\title{
Development, optimization, and validation of novel anti-TEM1/ CD248 affinity agent for optical imaging in cancer
}

\author{
Chunsheng Li ${ }^{1, *}$, Junying Wang ${ }^{1,5, *}$, Jia Hu${ }^{1}$, Yi Feng ${ }^{2}$, Kosei Hasegawa6, Xiaohui \\ Peng $^{1}$, Xingmei Duan ${ }^{1}$, Aizhi Zhao, John L. Mikitsh ${ }^{4}$, Vladimir R. Muzykantov ${ }^{3}$, \\ Ann-Marie Chacko ${ }^{3,4}$, Daniel A. Pryma4, Steven M. Dunn7, George Coukos ${ }^{1,7}$ \\ ${ }^{1}$ Ovarian Cancer Research Center, University of Pennsylvania \\ 2 Department of Cancer Biology, University of Pennsylvania \\ ${ }^{3}$ Institute for Translational Medicine and Therapeutics, University of Pennsylvania \\ ${ }^{4}$ Nuclear Medicine \& Clinical Molecular Imaging, Department of Radiology, University of Pennsylvania \\ ${ }^{5}$ Department of Immunology, Norman Bethune College of Medicine Jilin University \\ ${ }^{6}$ Saitama International Medical Center Saitama Medical University \\ ${ }^{7}$ Ludwig Cancer Research Center, University of Lausanne \\ * These authors contributed equally to this work \\ Correspondence to: Chunsheng Li, email: lich@mail.med.upenn.edu \\ George Coukos, email: gcks@mail.med.upenn.edu
}

Keywords: sCFv, TEM1, endosialin, optical imaging

Received: April 29, $2014 \quad$ Accepted: July 06, $2014 \quad$ Published: July 08, 2014

This is an open-access article distributed under the terms of the Creative Commons Attribution License, which permits unrestricted use, distribution, and reproduction in any medium, provided the original author and source are credited.

ABSTRACT

Tumor Endothelial Marker-1 (TEM1/CD248) is a tumor vascular marker with high therapeutic and diagnostic potentials. Immuno-imaging with TEM1-specific antibodies can help to detect cancerous lesions, monitor tumor responses, and select patients that are most likely to benefit from TEM1-targeted therapies. In particular, near infrared(NIR) optical imaging with biomarker-specific antibodies can provide real-time, tomographic information without exposing the subjects to radioactivity. To maximize the theranostic potential of TEM1, we developed a panel of all human, multivalent Fc-fusion proteins based on a previously identified single chain antibody (scFv78) that recognizes both human and mouse TEM1. By characterizing avidity, stability, and pharmacokinectics, we identified one fusion protein, $78 \mathrm{Fc}$, with desirable characteristics for immuno-imaging applications. The biodistribution of radiolabeled 78Fc showed that this antibody had minimal binding to normal organs, which have low expression of TEM1. Next, we developed a 78Fc-based tracer and tested its performance in different TEM1-expressing mouse models. The NIR imaging and tomography results suggest that the 78FC-NIR tracer performs well in distinguishing mouse- or human-TEM1 expressing tumor grafts from normal organs and control grafts in vivo. From these results we conclude that further development and optimization of 78Fc as a TEM1-targeted imaging agent for use in clinical settings is warranted.

\section{INTRODUCTION}

Antibody-based diagnostic and therapeutic strategies are entering center stage as cancer treatment options. While intact monoclonal immunoglobulins (mAbs) constitute the majority of US Food and Drug Administration (FDA) approved antibody-based therapeutics, minimal fragment derivatives, such as the single chain $\mathrm{Fv}$ ( $\mathrm{scFv}$ ) that target tumors have demonstrated promising therapeutic potential in recent clinical trials (reviewed here [1]). Rapid advances, both in the screening of human-derived antibody libraries, and in the engineering of scFv-based protein derivatives now provide great opportunities for developing highly specific multivalent antibody fragments 
tailored to meet the stringent functional demands required for various clinical applications.

Immuno-imaging with tumor biomarker-specific antibodies is a rapidly developing research area. Immunoimaging can provide vital information on tumor stages and tumor response without invasive treatments, and it can also help to screen for patients that are likely to benefit from specific targeted therapies. In fact, several ${ }^{124} \mathrm{I}$ - or ${ }^{89} \mathrm{Zr}$-labeled $\mathrm{mAb}$ radiopharmaceuticals have been approved by FDA in immuno-PET (positron emission tomography) and SPECT (single-photon emission computed tomography) imaging applications [2]. Recently, optical imaging has attracted increasing attention as an alternative imaging approach for cancer. Immuno-optical imaging requires no radioactivity, is able to acquire real-time intraoperative imaging information, and can be used for both two-dimensional imaging and three-dimensional tissue reconstruction [3]. For example, intraoperative detection of breast cancer [4] and lymph node mapping [5-9] within clinical settings is regularly performed using optical imaging with indocyanine green (ICG). Hence, due to its non-invasive and non-radioactive advantages, optical imaging using tumor biomarkerspecific antibodies is particularly well suited to serve as a complimentary imaging technique to PET/SPECT. In particular, by exploiting the unique properties of light at near infrared (NIR) wavelengths, the "NIR optical biopsy", in combination with endoscopy or camera, allows direct visualization of marker expression in live tissues in vivo, thus circumventing the need for histo- or cytological staining of specimens taken from target tissues. In addition, as optical imaging is less expensive and imposes no radioactive burden on the subject of study, it can be especially attractive as a tool for antibody development and optimization.

The success of immuno-optical imaging relies critically on the identification of robust biomarkers and the subsequent development of antibodies with the appropriate stability and pharmacokinetic profiles for imaging applications. In recent years, several markers associated with the tumor vasculature (TVM) have received considerable attention as therapeutic targets [1015]. Key drivers have been their low rates of mutation relative to cancer cells $[16,17]$, direct accessibility to exogenous agents via the circulation, and their compelling association with angiogenic processes shown to be essential for tumor disease progression. Blockade of the latter is clearly correlated with tumor regression and is an established anti-cancer strategy [18, 19]. To this end, multiple lines of evidence have suggested that Tumor Endothelial Marker 1 (TEM1/endosialin/CD248) is a promising TVM target: TEM1 is implicated in neo-angiogenesis [20,21], vascular cell adhesion and migration [22, 23], and tumor progression [24]; in breast cancer, TEM1 overexpression correlates with lymph node metastasis, recurrence and death [25]; in ovarian cancer, increased TEM1 expression was found in the endothelial cells and vasculature-associated leukocytes in the tumor microenvironment [26]; the expression levels of TEM1 are considerably higher in the tumor vasculatures of various cancers $[13,20,21,27-31]$ but below the detection limit $[20,21]$ in normal adult tissues; and TEM1 knockout did not impair any normal biological processes in mice [32]. In addition to its vascular expression in ovarian and other carcinomas, TEM1 has been shown to be upregulated in the tumor cells of sarcomas [33, 34]. Further, a humanized mouse monoclonal antibody targeting TEM1, MORAb-004 [21], is currently undergoing phase-1 clinical trials for the treatment of patients with various cancers. We previously reported the first immuno-PET imaging study in preclinical animal models using this $\mathrm{mAb}[35$, 36]. However, despite the obvious therapeutic interest, suitable imaging tools to explore the potential of TEM1 as a diagnostic marker have to-date not been reported otherwise.

We have recently isolated a TEM1-specific fullyhuman scFv, scFv78, which was shown to bind with high affinity to both human and mouse TEM1 [37], and thus to have relevance as a test molecule in preclinical models. It is widely considered, however, that the functional efficacy of the scFv format is often limited due to its small size and monovalency (reviewed here [1]). We have sought to exploit the TEM1 recognition potential of scFv78 for immuno-imaging applications by fusing it to an immunoglobulin Fc domain. Fc-fusion proteins often demonstrate a number of beneficial biological and pharmacological characteristics: firstly, the plasma half-life of the Fc-containing fusion proteins are often significantly improved due to slower renal clearance and enhanced interaction with salvage Fc receptors [38]; secondly, the presence of an Fc domain allows easy purification of the fusion protein by protein-G/A affinity chromatography [39]; finally, the Fc fragment is dimeric in the native state which serves to increase the avidity of the $\mathrm{scFv}$ fusion partner, potentially improving potency (sensitivity) and performance in demanding applications, such as those encountered in the clinic. Currently, several Fc-fusion proteins have undergone clinical testing and have demonstrated favorable pharmacokinetics, half-life and avidity towards their antigens (reviewed here [40]).

In this study we have engineered a panel of TEM1specific, fully-human, bivalent antibody-like reagents by fusing scFv78 with different domain components from the human immunoglobulin G1 (IgG1) Fc. We evaluated the affinities and stabilities of scFv78 and its derivatives and characterized their pharmacokinetic (PK) profiles in naïve and TEM1-positive graft bearing animals. Through these studies, we identified one construct, $78 \mathrm{Fc}$, as being a strong candidate for immuno-imaging applications. In two preclinical models where mouse TEM1 is either spontaneously upregulated or human TEM1 is expressed in tumor vascular xenografts, we show that in vivo NIR 
optical imaging using fluorochrome-labeled $78 \mathrm{Fc}$ can distinguish high-TEM1 expressing tumor grafts from normal organs. These findings support further clinical evaluation of $78 \mathrm{Fc}$ as an optical imaging agent in cancer patients.

\section{RESULT}

\section{Development and purification of oligomeric scFv78 -Fc fusion proteins}

Since the practical utility of many scFvs are often limited due to their small size, structural instability due to relatively weak variable domain interactions, and monovalency [1], we sought to construct novel oligomerised scFv78 variants more suitable for therapeutic and prognostic (theranostic) applications. To achieve this goal, we designed four multivalent $\mathrm{scFv}-\mathrm{Fc}$ fusion proteins: $78 \mathrm{~F}\left(\mathrm{ab}^{`}\right)$, 78CH2, scFv78-minibody (78mb), and scFv78-Fc (78Fc) (Fig 1A). While 78F(ab'), was generated by linking two scFv78 together via the IgG1 core hinge region (CPPCP), the other three variants were constructed by fusing different $\mathrm{Fc}$ regions to the C-terminal of scFv78. The calculated molecular weight of bivalent molecules of $78 \mathrm{~F}\left(\mathrm{ab}^{\prime}\right)_{2}, 78 \mathrm{CH} 2,78 \mathrm{mb}$, and $78 \mathrm{Fc}$ are $65 \mathrm{kDa}, 90 \mathrm{kDa}, 90 \mathrm{kDa}$, and $120 \mathrm{kDa}$, respectively. A $\mathrm{HA}$ tag was added to the $\mathrm{N}$ terminus of the proteins for easy purification and detection, and upstream addition of the signal peptide from Ig KappaV enabled the fusion proteins to be secreted and easily purified from the media of the host 293T expression cells (sup Fig 1). Fusion proteins were purified by incubating the conditioned culture media with anti-HA affinity matrix beads. For all fusion proteins, we were able to purify $0.5-1 \mathrm{mg} / \mathrm{L}$ protein at a purity $>90 \%$. Since the size exclusion HPLC (SE-HPLC) analysis of the purified proteins revealed additional peaks, suggesting the presence of aggregates/ multimers of the proteins (Fig 1B), we further analyzed the quarternary status of the proteins by polyacrylamide gel electrophoresis. Under reducing conditions, the migration of all scFv derivatives appeared consistent with their calculated molecular weights (Fig 1C). Under non-

\section{A}

\begin{tabular}{|c|c|c|c|c|c|}
\hline & 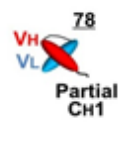 & 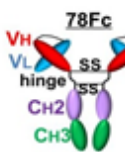 & 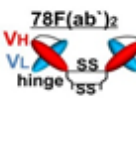 & 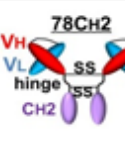 & 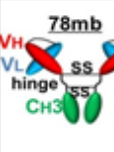 \\
\hline format & scFv & $\mathrm{scFv}-\mathrm{Fc}$ & scFv-hinge & $\mathrm{scFv}-\mathrm{CH} 2$ & scFv-CH3 \\
\hline MW & $27 \mathrm{kDa}$ & $120 \mathrm{kDa}$ & $65 \mathrm{kDa}$ & $90 \mathrm{kDa}$ & $90 \mathrm{kDa}$ \\
\hline valency & monovalent & bivalent & bivalent & bivalent & bivalent \\
\hline
\end{tabular}

\section{B}
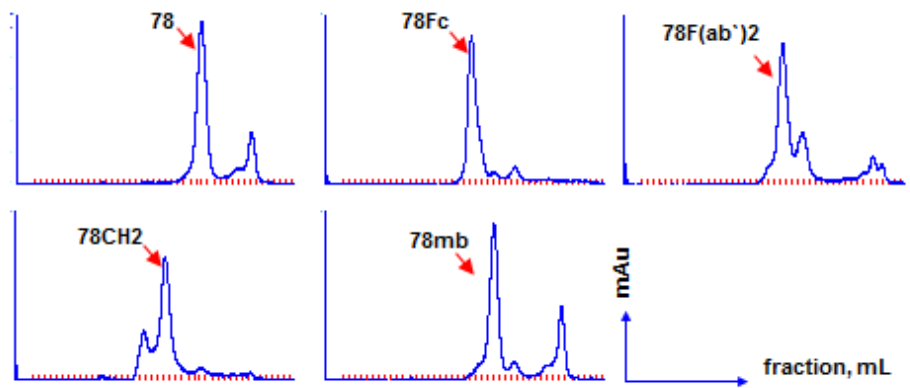

fraction, $\mathrm{mL}$

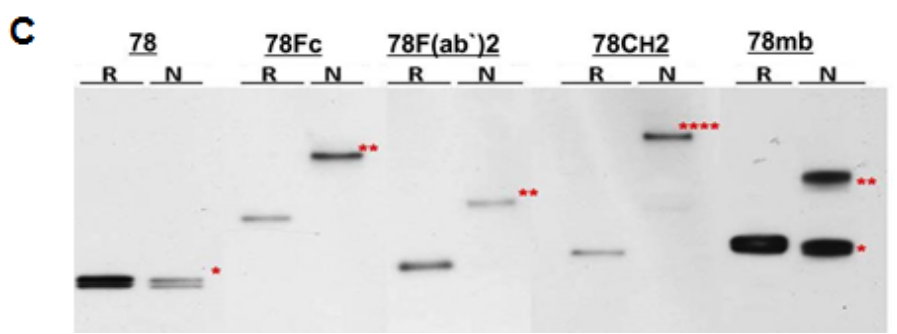

Fig.1: Development, purification, and characterization of scFc78 fusion proteins. A, Schematic representation of the domain organization and the predicted molecular weights and valencies of scFv78 and the four scFv78 fusion derivatives. B, SEC analyses of affinity purified scFv78 and the four scFv78 fusion derivatives. C, multivalent status of scFv78 and the four scFv78 fusion derivatives by Western blot analysis with anti-HA antibody. R: reducing conditions, $\mathrm{N}$ : non-reducing conditions. ${ }^{*}$ monomer, ${ }^{* *}$ dimer, $* * * *$ multimer. 
reducing conditions, while scFv78 remained monovalent, we observed apparent oligomerisation of the fusion proteins: for $78 \mathrm{Fc}$ and $78 \mathrm{~F}\left(\mathrm{ab}^{\prime}\right)_{2}$, the majority of protein appeared dimeric; for $78 \mathrm{CH} 2$, the majority $(>90 \%)$ of protein migrated with an apparent mass consistent with a tetramer; and for $78 \mathrm{mb}$, about $40 \%$ of the protein remained monomeric.

\section{scFc78-Fc fusion proteins have higher avidity to TEM1 than ScFv78}

It is well established that increases in valency can improve the avidity of an antibody. To measure the avidities of scFv78 and its derivatives under conditions that are more relevant to in vivo settings, we established a live-cell ELISA assay to measure the binding of the fusion proteins to cell-surface TEM1. Briefly, we first modified Mile-Sven1 (MS1), a TEM1-negative endothelial cell line, to express human TEM1 at a moderate level, with the saturated maximal binding capacity $\left(\mathrm{B}_{\max }\right)$ of $\sim 4 \times 10^{5}$ per cell. Different concentrations of scFv78 derivatives were then incubated with either control or TEM1 positive MS1 cells. Following washing, remaining molecules bound to the live cells at each concentration were detected by ELISA. Specific binding was observed when the concentration of fusion protein was as low as $0.1 \mathrm{nM}$, and non-specific binding was not observed below $10 \mathrm{nM}$ (Fig 2A). While all samples tested have comparable $\mathrm{B}_{\max }$, the fusion proteins all have lower apparent $\mathrm{K}_{\mathrm{d}}$ values than scFv78, consistent with higher oligomeric avidities to TEM1 (Fig 2B). However, the apparent oligomerisation of $78 \mathrm{CH} 2$ does not translate into the expected avidity gain, suggesting that this species may have steric or structural issues. Among all antibodies tested, $78 \mathrm{Fc}$ demonstrated the lowest $\mathrm{K}_{\mathrm{d}}$ value in sub-nanomolar range, which was $\sim 15$-fold lower than that of scFv78 (Fig 2B).

\section{The stability and pharmacokinetic profiles of scFv78 fusion proteins}

Good biophysical stability and appropriate serum half-life are generally considered important prerequisites for antibodies or antibody products destined for clinical applications. To evaluate the stability of the scFv78 fusion proteins, we first measured their thermal stability by incubating the purified proteins with SYBR orange under a temperature gradient from $20^{\circ} \mathrm{C}$ to $99^{\circ} \mathrm{C}$. Following incubation, the samples were analyzed by differential scanning fluorimetry (DSF), an assay employed to estimate protein degradation/unfolding and aggregation. The thermostability curves revealed that the melting temperatures $\left(\mathrm{T}_{\mathrm{m}}\right)$ of $\mathrm{scFv} 78$ and its derivatives were comparable (Fig 3A).

Next, we tested the in vitro serum stability of scFv78 fusion proteins by incubating the proteins in $100 \%$ human serum at $37 \mathrm{C}$ for up to 7 days. Samples were collected at different time points during incubation, and HA-agarose beads were used to capture the fusion proteins. Serum stabilities were measured by quantifying the amount of bead-bound recovered protein by western blot analysis. In the presence of serum at $37^{\circ} \mathrm{C}$, recoverable levels of scFv78, 78F(ab') ${ }_{2}, 78 \mathrm{CH} 2$, and $78 \mathrm{Fc}$ remained relatively consistent throughout the 7-day incubation; yet, the amount of bead-bound $78 \mathrm{mb}$ decreased significantly after two days of incubation (Fig 3B). This apparent instability of $78 \mathrm{mb}$ may be a consequence of its heterogeneous composition (Fig 1C). These observations suggest that, with the exception of $78 \mathrm{mb}$, the scFv78 fusions possess sufficient physicochemical stability to make them attractive candidates for in vivo applications.

Finally, we conducted in vivo pharmacokinetic studies to determine the blood clearance rates of scFv78 fusion proteins. scFv78 and its fusion proteins were first radiolabeled with iodine-125 $\left({ }^{125} \mathrm{I}\right)$. When injected into
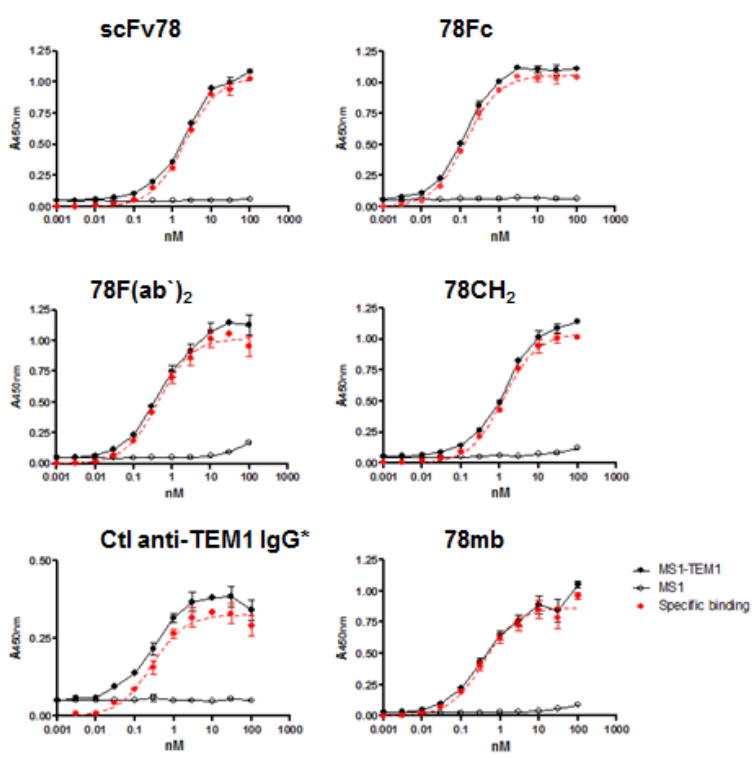

B

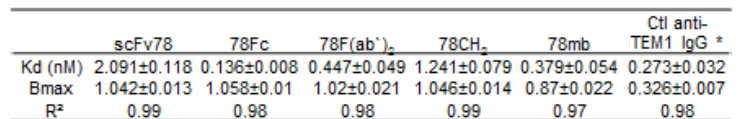

Fig.2: scFv78 fusion proteins demonstrate higher avidity to cell-surface TEM1. A, The dose-dependent binding curves of scFv78 and its derivatives. Cell-surface binding activity in control (MS1) or TEM1-expressing cells (MS1-TEM1) was measured by a live cell-based ELISA assay. TEM1-specific binding was calculated as the difference between binding to the control and TEM1-expressing protein. The control anti-TEM1 IgG is a biotinylated humanized mouse IgG1. B, A summary of the calculated $\mathrm{K}_{\mathrm{d}}$ and $\mathrm{B}_{\text {max }}$ of the scFv78 and scFv78 derivatives. Anti-HA HRP was used as the secondary antibody in ELISA for all proteins except for the control anti-TEM1 IgG which required strepavidin-HRP. * indicates the different secondary antibody used. 
naïve nu/nu mice, serum concentrations of these ${ }^{125} \mathrm{I}-$ labeled Fc fusion proteins decreased in a typical biphasic manner (Fig 3C). While scFv78 was rapidly eliminated from circulation, presumably via glomerular clearance, scFv78-derived fusion proteins were cleared from plasma much slower (fast-phase $\mathrm{t}_{1 / 2}$ of $\mathrm{scFv} 78$ and $78 \mathrm{Fc}$ are 0.04 $\mathrm{h}$ and $0.31 \mathrm{~h}$, respectively). Importantly, the slow-phase half-life of $78 \mathrm{Fc}$ is about $5.1 \mathrm{~h}$, long enough to serve as an imaging tracer but short enough to avoid antibodyretention-associated imaging background as seen with many full-length immunoglobulins.

\section{Codon-optimization, scale-up production and purification of the $78 \mathrm{Fc}$ fusion protein}

The observation that $78 \mathrm{Fc}$ displays encouraging in vitro thermal and serum stability behavior, in addition to possessing the highest avidity to TEM1 and a favorable murine PK profile, prompted us to investigate further the suitability of $78 \mathrm{Fc}$ for imaging applications by extending the study into preclinical mouse models. As a first step, we sought to improve the HEK cell expression yield and purification efficiency of $78 \mathrm{Fc}$. We first improved the Homo sapiens Codon Adaptation Index (CAI) score of the $78 \mathrm{Fc}$ coding sequence to 0.96 (GeneOptimizer; Life Technologies). Subsequently, cis-acting sites (such as splice sites, RNA instability motifs, TATA box, GChi and AT-hi regions, ribosomal entry sites) that could potentially inhibit protein expression were removed wherever possible. Finally, we adjusted the GC content to $63 \%$ to prolong mRNA half-life. These measures were sufficient to increase the yield of $78 \mathrm{Fc}$ from $0.5-1$ $\mathrm{mg} / \mathrm{L}$ for the un-optimized gene, to $15-20 \mathrm{mg} / \mathrm{L}$ for the optimized gene expressed in HEK 293 Freestyle cells. We next sought to compare the purification capture efficiencies of anti-HA and Protein G matrices. 78Fc protein was first enriched with anti-HA agarose or Protein $\mathrm{G}$, and the purified proteins were then subjected to size exclusion chromatography (SEC) prior to concentration of peak fractions (Fig 4A). The yields and purities of the final concentrated proteins were compared by SDS-PAGE using Western blot analysis and Coomassie dye staining (Fig $4 \mathrm{~B}, \mathrm{C})$. The results indicated that both affinity approaches were equally effective for purification with final purities exceeding 95\%. Since purification using Protein-G is more cost-effective, we decided to use Protein-G capture combined with SEC to purify large quantities of $78 \mathrm{Fc}$ for in vivo testing.
A

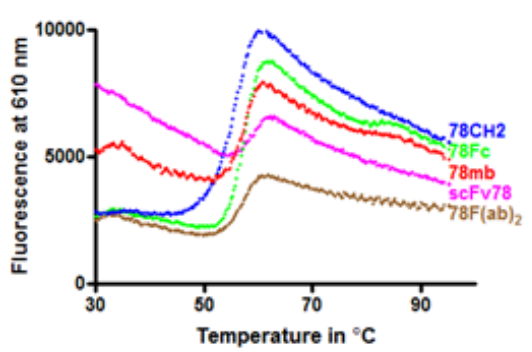

C

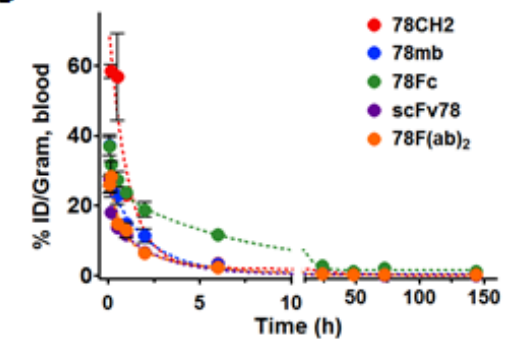

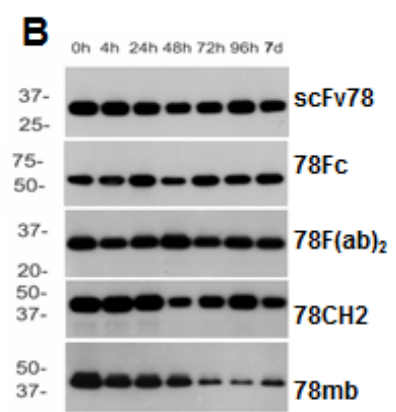

\begin{tabular}{lllllll}
\hline & scFV78 & $78 \mathrm{Fc}$ & $78 \mathrm{CH} 2$ & $78 \mathrm{mb}$ & $78 \mathrm{~F}(\mathrm{ab})_{2}$ & lgG (004) \\
\hline Fast & 0.04 & 0.31 & $\sim 0.086$ & 0.024 & 0.36 & 1.9 \\
\hline slow & 1.68 & 5.13 & 1.81 & 1.46 & 2.37 & 109.2 \\
\hline $\mathrm{R}^{2}$ & 0.99 & 0.99 & 0.93 & 0.98 & 0.96 & 0.95 \\
\hline
\end{tabular}

Fig.3: The stability and pharmacokinetic profiles of scFv78 and its derivatives. A, Thermal stability curves of the antibody variants. Differential scanning fluorimetry was used to measure protein aggregation and degradation. B, Serum stability assay of scFv78 and its derivatives. Purified antibody variants were incubated with $100 \%$ human serum for up to 7 days at $37^{\circ} \mathrm{C}$. Samples taken at different time points were then analyzed by Western blot with anti-HA antibody. C, Pharmacokinetics of ${ }^{125}$ I-labeled anti-TEM1 variants in naïve nu/ nu mice. The half-lives (fast and slow, in hours) deduced from the study is underneath. 


\section{$78 \mathrm{Fc}$ biodistribution in vivo}

Since scFv78 binds to both human and mouse TEM1 [37], we reasoned that mouse would be a valid preclinical model species for evaluating the tissue uptake and biodistribution of $78 \mathrm{Fc}$. To characterize the tissue uptake and biodistribution of $78 \mathrm{Fc}$ in naïve mice, we first radiolabeled $78 \mathrm{Fc}$ and $\mathrm{scFv} 78$ with ${ }^{125} \mathrm{I}$. While the affinity of scFv78 to TEM1 decreased significantly upon conjugation (Fig 5A), the apparent affinity of radiolabeled $78 \mathrm{Fc}$ was still in the nanomolar range, only slightly lower than that of its unlabeled counterpart (Fig $5 \mathrm{~B})$. The radiolabeled $78 \mathrm{Fc}$ was injected into naive mice and samples from multiple organs, including full blood, thyroid gland, heart, lung, kidney, spleen, liver, brain, uterus and ovary, were collected at different time points. The quantity of $78 \mathrm{Fc}$ protein present in the various tissues was assumed to correlate with the measured radioactivity. While there was an acute increase of measurable radioactivity following the $78 \mathrm{Fc}$ injection, the signals observed in normal mouse organs were seen to decrease rapidly with time, consistent with the absence of targetmediated retention and reflecting the low detectable levels of TEM1 mRNA in these tissues (Fig 5D). Interestingly, one exception was the uterus where apparent retention/ accumulation of label appeared to correlate with a modest level of mouse TEM1 mRNA. It is worth noting that while kidney and liver are considered major clearance routes for $\mathrm{scFv}-\mathrm{Fcs}$, we did not detect any signal enrichment in these two organs. In tumor-bearing animals, we observed that $78 \mathrm{Fc}$ was not retained in normal tissues but was clearly enriched in TEM1-expressing tumors (Sup Fig 2). The observation that low levels of tracer accumulation occurred in the thyroid (Fig 5C), a phenomenon which we have observed previously [38,39], can be attributed to the dehalogenation of the ${ }^{125} \mathrm{I}$-labeled $78 \mathrm{Fc}$. Taken together, this data suggests that off-target or non-specific binding of $78 \mathrm{Fc}$ is unlikely to be a confounding factor for in vivo imaging.

\section{$78 \mathrm{Fc}$ as a tracer for optical imaging in murine TEM1-expressing lung tumor models}

As a rapidly developing technology, optical imaging is becoming a promising diagnostic modality in cancer management. To evaluate $78 \mathrm{Fc}$ as an optical imaging tool, we first generated $78 \mathrm{Fc}$-fluorochrome conjugates via two different coupling methods: N-hydroxysuccinimide (NHS)-esterification, and thiol (-SH, sulfhydryl) reactive maleimide chemistry. We chose VivoTag-S750 as the conjugating fluorochrome because the near infrared wavelength is ideal for both in vitro and in vivo biological imaging applications. In addition, with the fluorescence tomography (FMT) imaging systems, VivoTag-S750 can also provide quantitative, three-dimensional information of in vivo target tissues. While the fluorochrome- $78 \mathrm{Fc}$ conjugate prepared with NHS chemistry effectively ablated the ability of $78 \mathrm{Fc}$ to bind to TEM1 (Fig 6A), the impact of maleimide coupling was far less dramatic, resulting in only a 3-fold reduction in apparent affinity for this conjugate (hereafter designated as $78 \mathrm{Fc} 750$ ) as compared to the underivatised $78 \mathrm{Fc}$.

Next, we tested 78 Fc750 in a TC1 mouse lung xenograft tumor model. While TC1 is a mouse lung metastasis cell line that expresses very little TEM1, TC1 tumor engrafts have high TEM1 mRNA expression (Fig 6B). To establish the TC1 tumor model for optical imaging, we stably transfected parental TC1 cells with firefly luciferase and sorted the luciferase-positive population. The luciferase expression allowed us to track tumor location and growth via bioluminescent signal detection in live animal imaging. Luciferase-positive TC1 cells $\left(1 \times 10^{5}\right)$ were inoculated subcutaneously at a single site on the flanks of nude mice $(n=5)$. One week after the inoculation, successful engraftment of TC1 tumors was

A

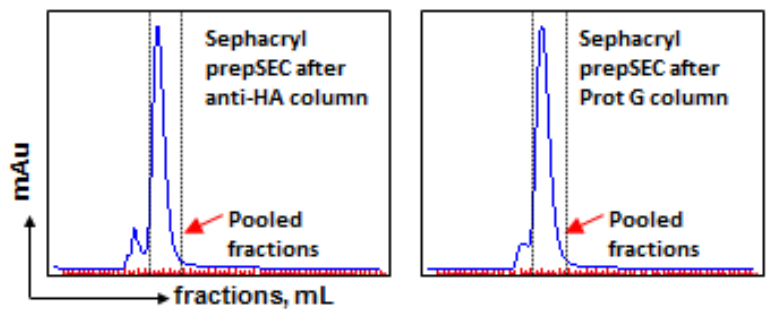

B

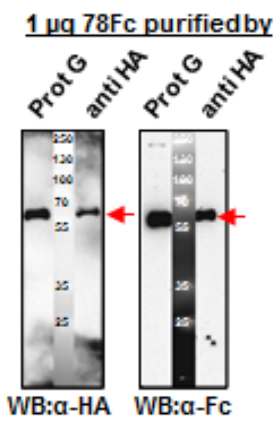

C

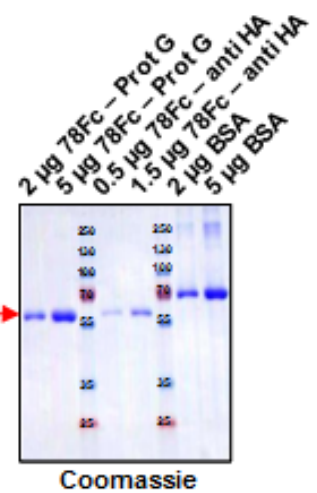

Fig.4: Comparison of two purification methods for scale-up production of $78 \mathrm{Fc}$ fusion protein after codonoptimization. Scale up production of fusion protein $78 \mathrm{Fc}$ was performed after codon optimized by adapting codon bias of Homo sapiens genes with GeneOptimizer (Life technology). A, Elution profiles on SEC columns after affinity purification with anti-HA (left panel) or Protein G (right panel) methods. 78Fc protein elution fractions which were pooled (red arrowhead) are indicated with dotted-lines. B and C, Comparison of the purification efficiencies of anti-HA and Protein G methods by Western blot analysis (B) and Coomassie blue staining (C). A yield of $15-20 \mathrm{mg} / \mathrm{L}$ were achieved post optimization from 293 Freestyle cells (Invitrogen) compare with $0.5-1 \mathrm{mg} / \mathrm{L}$ before optimization with purity $>95 \%$. 
A

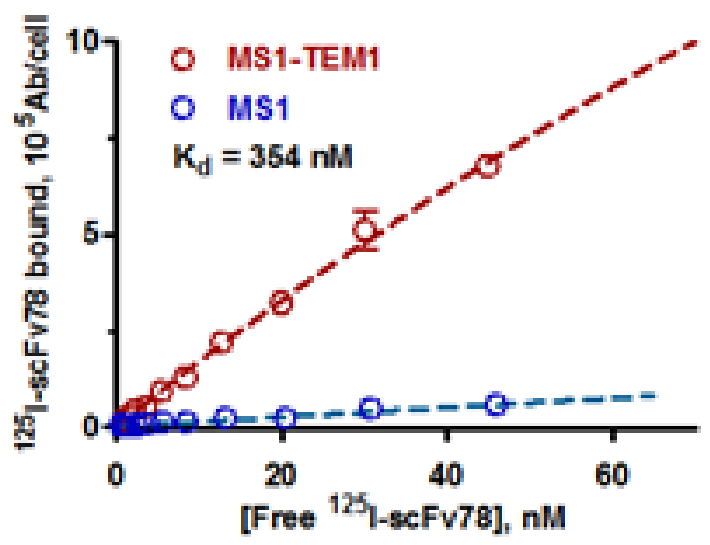

B

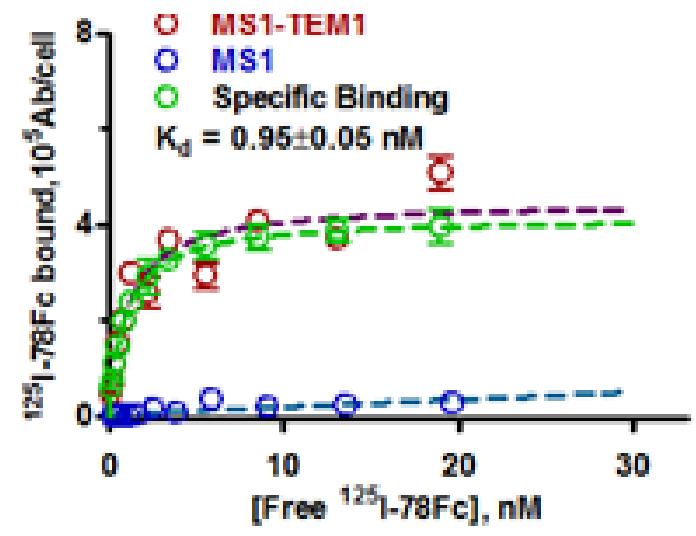

C
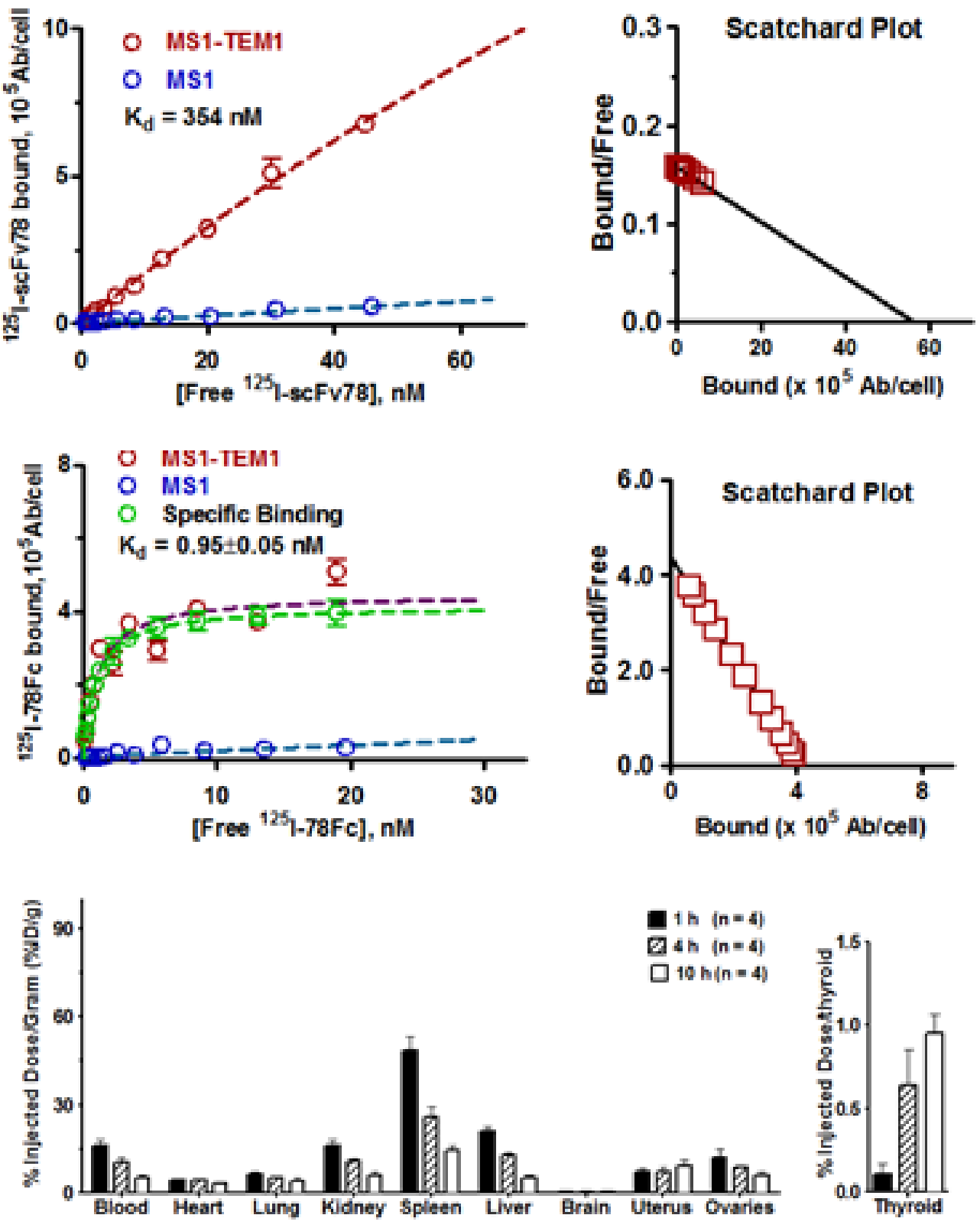

D

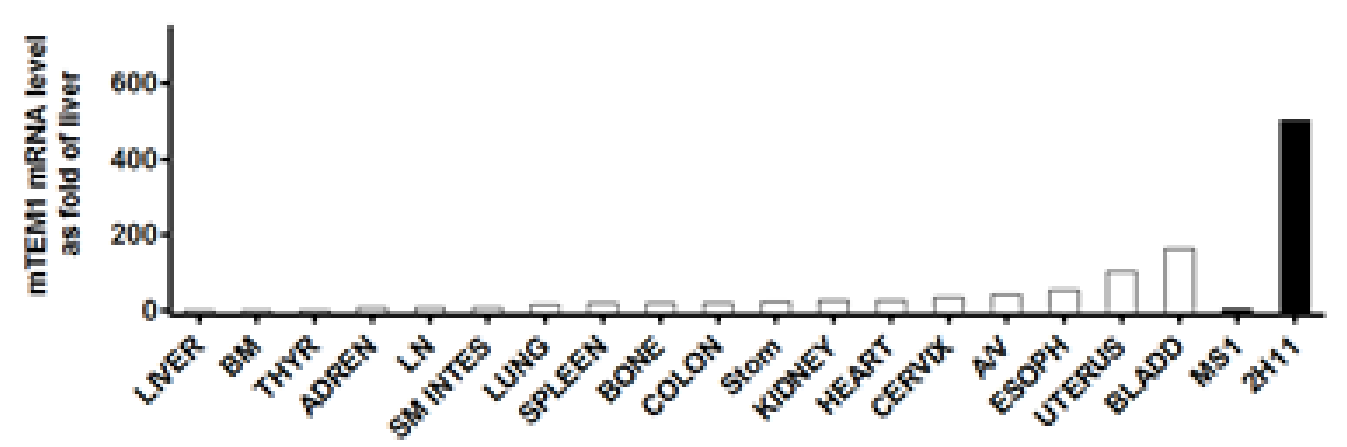

Fig.5: 78Fc demonstrates little off-target binding in major mouse organs in vivo. $\mathrm{A}, \mathrm{B} \mathrm{K}_{\mathrm{d}} / \mathrm{B}_{\max }$ binding studies of radiolabeled anti-TEM1 scFv78(A) and 78Fc(B). The avidity of 78Fc to TEM1 was not significantly affected by ${ }^{125} \mathrm{I}$ labeling. C, Biodistribution profile of ${ }^{125} \mathrm{I}-78 \mathrm{Fc}$ protein in naïve mice, showing no TEM1-specific accumulation in major organs. Left, \% injected dose/gram in major organs; right, \% injected dose/gram in thyroid. D, muTEM1 mRNA level in normal mouse organs determined by qPCR. TEM1 expression in liver was set as 1 (open bars). MS1 and 2H11 (dark bars) are used as negative and positive controls. 
confirmed by bioluminescent imaging and the animals were then injected with $78 \mathrm{Fc} 750$ intravenously into the retro-orbital complexes. Near infrared optical images were acquired from 10 minutes up to 3 days post-injection of the tracer. Encouragingly, these TC1 tumors containing elevated levels of TEM1 mRNA were easily distinguished from surrounding normal tissues by NIR optical imaging using the $78 \mathrm{Fc} 750$ conjugate (Fig 6C). However, it should be noted that significant NIR signals were observed in the liver and kidneys of these tumor-bearing animals (Sup Fig 3). Since we did not find any enrichment of the ${ }^{125}$ I-labeled $78 \mathrm{Fc}$ in the liver or kidney from the preceding biodistribution study, we attribute this apparent staining to the known instability of plasma accessible maleimide linkages [41] and to probable maleimide exchange reactions between $78 \mathrm{Fc} 750$ and plasma components that direct the accumulation of the liberated Vivotag-S750 to the key sites of excretion and metabolism. Similar phenomena have been described elsewhere [42, 43].

In order to confirm the above findings we established an alternative TC1 lung metastasis mouse model by inoculating the luciferase-positive TC1 cells intravenously into nude mice. The TC1-derived metastatic lesions formed seven days after cell inoculation and were confirmed by bioluminescent imaging. The TEM1 mRNA expression in TC1 lung metastasis lesions was higher than in the surrounding lung tissue (Fig 6D). In this model, NIR optical imaging with 78 Fc 750 was able to clearly
A

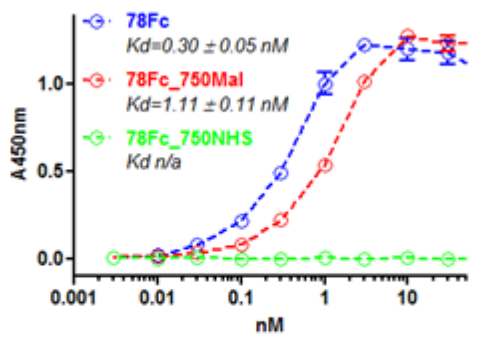

B

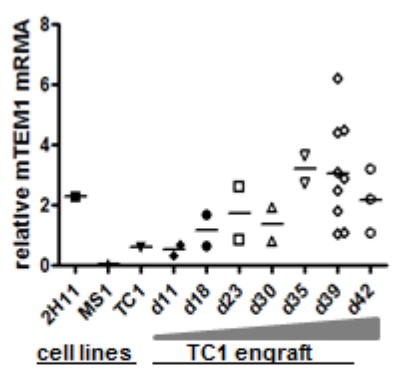

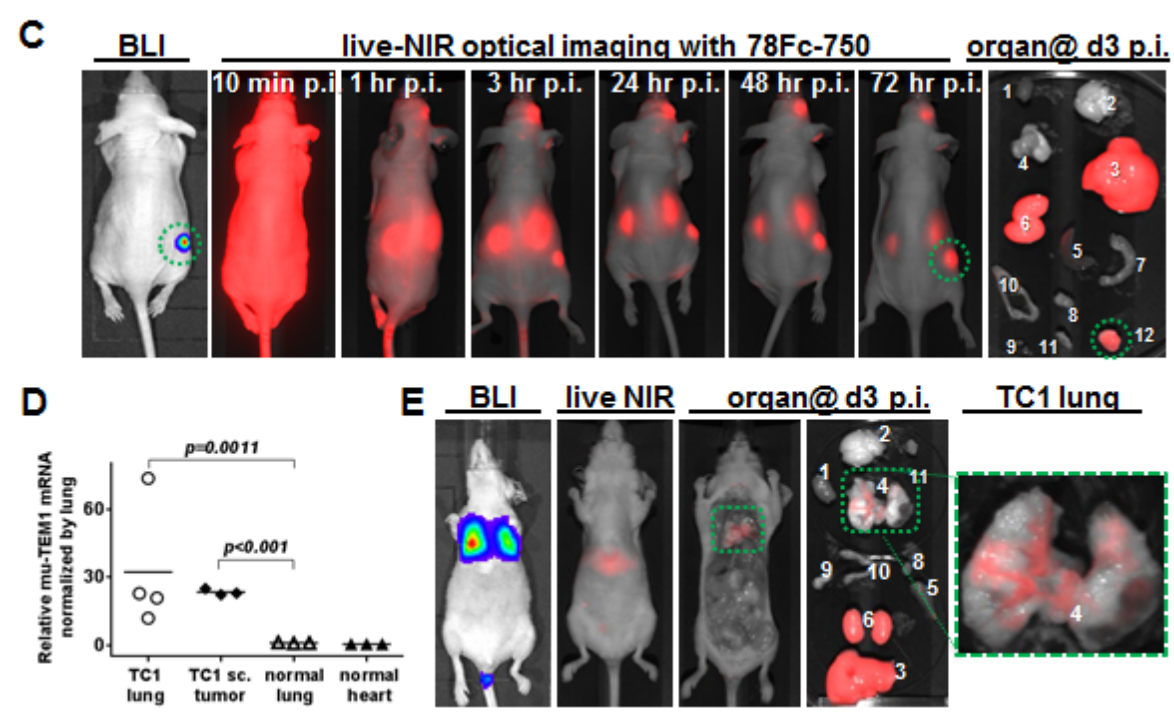

Fig.6: 78Fc as an NIR optical imaging tracer in a murine TEM1-expressing lung cancer xenograft model. A, Live cell ELISA analysis of $78 \mathrm{Fc}$ labeled with Vivotag 750 via either maleimide (red) or NHS (green) linkage. Blue indicates the binding activity of unlabeled 78Fc. B, TC1-derived subcutaneous tumor grafts express high level of muTEM1. $10^{4} \mathrm{TC} 1$ cells were injected subcutaneously into B6 mice and tumors were harvested at the indicated time (up to $6 \mathrm{wks}$ ). muTEM1 mRNA levels in tumor and parental cells were measured by qRT-PCR, and 2H11 and MS1 cells were used as positive and negative controls, respectively. C, in vivo bioluminescence imaging (BLI) and 78Fc750-based live NIR optical imaging in a TC1 subcutaneous tumor model ( $\mathrm{n}=5)$. $78 \mathrm{Fc} 750$ was given via retro orbital injection $(5 \mathrm{mg} / \mathrm{kg}$ in $100 \mathrm{uL}$ ) and a longitudinal study of NIR imaging was performed up to 3 days post injection ( $\mathrm{n}=5)$. Green circle, muTEM1+ positive tumor. 1. heart; 2.brain; 3. liver; 4. lung; 5. spleen; 6. kidney; 7. small intestine; 8. bladder; 9. ovary; 10 . uterus; 11. thyroid; 12 . TC1 sc. xenograft. Residual tracer was observed at the injection site (retro-orbital complexes). D, TC1 lung metastatic lesions express higher levels of muTEM1 than normal tissue in the lung. E, in vivo bioluminescence imaging (BLI) and 78Fc750-based live NIR optical imaging in a TC1 lung metastasis model. $78 \mathrm{Fc} 750$ was given via retro orbital injection $(5 \mathrm{mg} / \mathrm{kg}$ in $100 \mathrm{uL})$ and a longitudinal study of NIR imaging was performed at 3 days post injection ( $\mathrm{n}=5)$. From left: ventral view of mouse BLI showing TC1 lung metastasis at day0; live animal NIR at day2 p.i. of 78Fc750; ventral view at day3 p.i. (postmortem) of same animal with liver and kidneys removed to show lung signal; all harvested organs including liver and kidneys; close up view of the lung. Green box, muTEM1+ positive lung tumor. 1. heart; 2.brain; 3. liver; 4. lung; 5. spleen; 6. kidney; 7. small intestine; 8. bladder; 9. ovary; 10. uterus. 
distinguish the TC1-derived lung lesions from surrounding healthy tissues (Fig 6E).

\section{$78 \mathrm{Fc}$ as a tracer for optical imaging in human TEM1-expressing tumor vascular model}

Next, we sought to evaluate the utility of 78 Fc 750 for imaging the human TEM1-expressing tumor vasculature using a xenograft model we established previously $[35,36]$. In this model, luciferase-expressing control MS1 cells (MS1) or human TEM1-positive MS1 cells (MS1-hTEM1) were injected into opposite flanks of the same nude mice to grow control or TEM1-expressing tumor vascular grafts. Since mouse TEM1 expression remains low in these huTEM1-expressing tumor grafts (Fig 7A, B), we reasoned that this model could be used to evaluate the performance of $78 \mathrm{Fc} 750$ in detecting
hTEM1-expressing grafts with NIR optical imaging. One week after grafting, the control and hTEM1-expressing MS1 vascular grafts were first assessed by bioluminescent imaging (BLI) (Fig 7C), before injecting 78Fc750 tracer for longitudinal NIR optical imaging. In common with the above biodistribution study in naive mice, the infrared signal in normal healthy organs, such as the heart, lung, or hTEM1-negative graft, was quickly cleared and became negligible within one day after tracer injection. In contrast, we detected intense and long-lasting fluorescence in hTEM1-positive grafts (Fig 7C).

Beyond 2-dimensional (2D) planar BLI, recent advancements include the ability to acquire 3-dimensional (3D) diffuse luminescence tomographic images (3D DLIT). To further confirm the specific localization of $78 \mathrm{Fc}$ to hTEM1-positive grafts, we conducted threedimensional imaging with DLIT (bioluminescent source reconstruction for spatial information of TEM1+ and
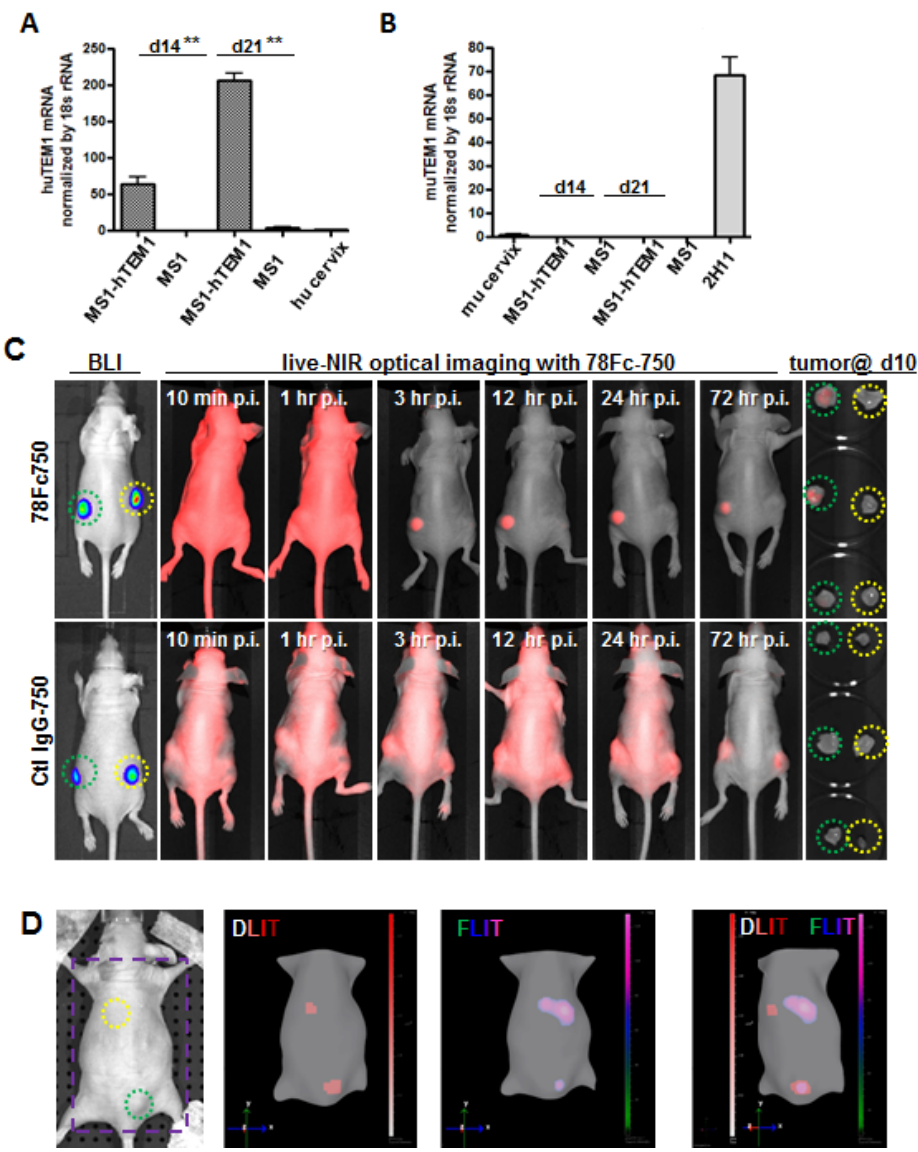

Fig.7: 78Fc as an NIR optical imaging tracer in the human TEM1-expressing tumor vascular model. Human (A) and mouse TEM1 mRNA (B) expression in control and hTEM1 expressing tumor grafts. TEM1 mRNA levels were evaluated with qRTPCR. TEM1 expression in normal human or murine cervix was normalized to 1. 10 ${ }^{7}$ MS1-huTEM1 or control MS1 cells were injected subcutaneously into nude mice on the left or right flanks, respectively $(n=3)$, and tumor grafts were harvested after the indicated time (2-3 weeks). huTEM1-positive tumor grafts express muTEM1 at similar levels to that of control tumor grafts. C, in vivo bioluminescence imaging (BLI) and 78Fc750- or IgG-750-based live NIR optical imaging in huTEM1-positive and control tumor grafts ( $\mathrm{n}=3$ per group). Green circle, MS1-TEM1 tumor; yellow circle, MS1 control tumor. D (Also in Sup videos), 78Fc750 BLI and NIR tomographic imaging in mice grafted with MS1-huTEM1 (lower) and MS1 (upper) in nude mice. Bioluminescent signals overlap with infrared signals only in the huTEM1-positive tumors. From left, picture (area inside the purple square is used for 3D dual modality imaging to regenerate mice surface), 3D reconstructions of bioluminescence (DLIT) and NIR fluorescence (FLIT); superimposed DLIT with FLIT. $\mathrm{n}=5$. 
control engrafts) and FLIT (NIR fluorescence source reconstruction for spatial information of $78 \mathrm{Fc} 750$ tracer), and co-registration of the DLIT and FLIT voxels. We found that the bioluminescent and NIR fluorescence signals overlapped only at the site of hTEM1-positive grafts (Fig 7D, supplementary videos). Similar to the TC1 models, fluorescence was observed in the livers of these mice (Sup Fig 4). These observations demonstrated that 78 Fc750 was specifically enriched in hTEM1-positive tissues.

\section{DISCUSSION}

Antibodies now represent an established class of therapeutic reagents capable of inhibiting tumor growth and inflammatory disease progression in the clinic, with new registrations growing year on year. Increasingly however, antibodies are also being recruited as immunemodulating agents, vehicles for targeted delivery, and as imaging agents for detecting and staging tumors, and for monitoring treatment response. In recent years, indium-111 satumomab pendetide (CYT-103), technetium99m nofetumomab merpentan (Verluma), technetium-99m arcitumomab (IMMU-4), indium-111 pentetreotide, and indium-111 capromab pendetide have been approved by the FDA as imaging agents for single-photon emission computed tomography (SPECT) in various cancers [2]. In addition, the radiolabelled derivatives of a growing number of therapeutic mAbs, including anti-CD44v6 (U36) [44], anti-cMet (DN30) [45], anti-carbonic anhydrase IX (G250) [46-48], anti-fibronectin (L19SIP)[49], anti-IGF-1R (R1507) [50], anti-PSMA (J591 and 7E11) [51, 52], anti-CD105 (TCR105) [53], antiEGFR (cetuximab) [54, 55], anti-CD20 (inbritumumab tiuxetan, rituximab) [56, 57], anti-VEGF (bevacizumab) [58, 59], and anti-HER2 (trastuzumab) [60-62] have been intensively evaluated in preclinical and clinical immunoPET studies.

Although immuno-imaging with mAbs has met with some success [36], the large size of intact immunoglobulins effectively restricts their renal clearance which, together with Fc-recycling mechanisms, often results in prolonged circulating half-lives and a background of radioactivity that can persist for time frames that are incompatible with short duration high contrast imaging of specific target tissues. To reduce the half-life of circulating antibodies, extensive efforts have been directed towards developing antibody-based reagents with fewer domains and reduced size $[63,64]$. The scFv minimal binding unit has featured heavily as a building block in such strategies (reviewed in [65]). Whereas scFvs themselves are considered poor reagents for imaging purposes, due mainly to a combination of rapid clearance and limited monovalent affinity, significantly better performance has been reported for several derivative scFv formats including $\mathrm{scFv}$ monomers conjugated to PEG or albumin,
$\mathrm{scFv}$ dimers (diabodies), scFv- $\mathrm{CH} 3$ dimers (minibodies) and $\mathrm{scFv}-\mathrm{Fc}$ dimers. One established strategy for domain reduction, and the subject of this work, is the design and construction of Fc-fusion proteins that comprise the Fc domain of an immunoglobulin and a (poly)peptide that possesses high affinity for the antigen of interest [66]. Such artificial constructs generally have reduced size and physicochemical and/or metabolic stability when compared alongside a native soluble immunoglobulin. Accelerated clearance for such molecules, although not expected per se, may arise from a combination of moderately improved renal clearance and/or degradative mechanisms, both endosomal and plasma-driven, which are dependent on the nature of the individual fusion. Fcfusion proteins with such properties may display higher blood clearance rates and have improved utility as imaging reagents. Though TEM1 is a well-validated tumor vascular marker and a promising theranostic target, currently there is only one chimeric, hTEM1-specific mAb undergoing clinical trials in patients with multiple types of cancer. To maximize the translational potential of TEM1, we have identified a potent TEM1-specific $\mathrm{scFv}$, scFv78, arising from yeast display and FACS-based screening [37], and have explored the contribution of four different valencyenhancing IgG1 Fc domain fusion arrangements to stability, avidity and pharmacokinetics.

For an antibody to perform well in imaging applications, it has to fulfill many criteria. Principally, it needs to maintain its avidity to the antigen after labeling. Here we observed that, unlike scFv78, which totally lost its binding to TEM1 upon radiolabeling, $78 \mathrm{Fc}$ retained high affinity binding following both radio- and fluorochromelabeling. Additionally, an antibody needs to have a favorable PK clearance profile for imaging applications. Although murine PK data of antibody-related molecules is considered unreliable for extrapolating clearance rates to humans [67], the blood clearance rate of around 5 hours for $78 \mathrm{Fc}$ in mice observed in our study, suggests that it may be possible for patients to be imaged within 24 hours following the tracer injection. Finally, to minimize potential off-target toxicity and masking, an antibody reagent must show minimal retention in non-target tissues. The evaluation of this criterion is challenging in commonly used preclinical models as many antibodies recognize only their cognate human antigens. In our case, since scFv78 recognizes both human and mouse TEM1, we reasoned that a mouse model would be relevant and informative in evaluating the bio-distribution and imaging performance of $78 \mathrm{Fc}$. In biodistribution studies, ${ }^{125} \mathrm{I}-78 \mathrm{Fc}$ demonstrated negligible uptake by critical tissues such as heart, lung, kidney, liver, and brain, and this was also the case for NIR imaging with 78Fc750. The observed nonspecific signals in liver and kidney were most likely due to liberation and metabolism of the tracer, which could potentially be addressed using more optimal conjugation and linker chemistries. This finding is consistent with the 
fact that most adult normal tissues express very low level of TEM1 [68], and it also suggested that 78Fc has very little off-target binding that can interfere with its imaging applications.

To further evaluate $78 \mathrm{Fc}$ as an imaging tool, we tested in two different mouse models: TC1 lung metastasis model, in which TC1 tumor grafts have high expression of mouse TEM1; and hTEM1 expressing tumor vascular model, in which human TEM1-expressing endothelia cells formed hTEM1 expressing tumor vasculature. In both models, there was only negligible amount of signals in normal mouse organs like heart, lung and brain; however, in TEM1-positive grafts, we observed strong and longlasting near infrared signals. Therefore, it is strongly suggested that one of the $\mathrm{scFv}-78$ based fusion protein we designed here may have a great potential as an optical imaging tool for clinical uses. One should note that unlike the biodistribution study with ${ }^{125} \mathrm{I}$-labeled $78 \mathrm{Fc}$, where no normal organ showed any sign of antibody retention, our optical imaging studies revealed strong fluorescent signals in liver and kidney. This signal most likely reflects the known instability of plasma accessible maleimide linkages and maleimide exchange between $78 \mathrm{Fc} 750$ and plasma components, thusleading to the accumulation of the liberated fluorochrome at key sites of excretion and metabolism. In a previous study with a HER2/Neu antibody, maleimide-conjugated linkers were shown to readily exchange with reactive thiols on albumin, free cysteine and glutathione, with the local charge context of the cysteine conjugation site also influencing the stability of the succinimide ring [41]. Similar observations of apparent liver and kidney localization have been reported for other optical imaging tracer conjugates, for example the commercial product Transferrin-Vivo750 (Perkin Elmer) and related conjugates [42, 43]. Thus, the chemical and structural dynamics of the conjugation site can influence antibody conjugate performance by modulating the stability of the antibody-linker bond, and contributing to non-specific background fluorescence in whole-body imaging applications. Further studies using conjugates stabilized by alternative chemistries and fluorochromes with improved free clearance profiles are clearly warranted.

NIR imaging has generally been considered practical only for tumors close to the body surface due to signal penetration limitations. However, recent technological advances are now challenging this perception by extending the utility of the approach to the imaging of internal organs in both pre-clinical and clinical settings [69-74]. As of June 2014, NIR imaging features in 14 clinical trials in intraoperative or endoscopic settings (www.clinicaltrials. gov). Two trials, NCT02129933 and NCT02113202, are concerned with evaluating, respectively, Bevacizumabconjugated NIR tracers in patients with esophageal cancer and adenomatous polyposis.. Based on the encouraging results we have obtained using $78 \mathrm{Fc}$-based NIR imaging reagents in pre-clinical models, further development activities are underway in order to maximize the translational potential of this antibody.

In summary, optical imaging is emerging as an important alternative to established radio-imaging technology. Immuno-optical imaging can provide accurate and specific information regarding the target tissue without invasive treatment or exposing the patient to radioactivity. It can also provide real time, spatial information regarding biomarker expression, which can help physicians to make clinical decisions during operations and guide treatment. In the current study we have demonstrated encouraging preliminary optical imaging results for a novel antiTEM1 Fc-fusion reagent in a preclinical setting. Further optimization of the fluorochrome and conjugation chemistry is clearly warranted. Additionally, given that $78 \mathrm{Fc}$ can distinguish both human and murine TEM1positive lesions from control lesions and surrounding normal tissues, our study also paves the way for developing $78 \mathrm{Fc}$ as a tracer for TEM1-targeted immunoPET in both preclinical and clinical applications.

\section{METHODS}

\section{Reagents and antibodies}

Goat $\mathrm{pAb}$ to HA tag (HRP) antibody was from Abcam. Streptavidin HRP was from BD Biosciences. Biotinylated MORAb004 (humanized mouse IgG1 recognize human but not mouse TEM1) was produced by Morphotek Inc. pcDNA 3.3/3.4 vector, FreeStyle ${ }^{\mathrm{TM}}$ 293 Expression medium, Freestyle MAX reagent and OPTI PRO serum free medium were from Invitrogen. Anti-HA affinity matrix and HA peptide were from Roche. Silverquest staining kit was from Invitrogen. Sureblue TMB microwell peroxidase substrate and TMB stop solution were from KPL. HA Tag IP/Co-IP Kit was from Pierce Thermo Scientific. VivoTag-S 750-MAL and VivoTag-S 750 fluorochrome is from Perkin Elmer. Taqman qRT-PCR primers are from Applied Biosystems.

Bicistronic lentiviral vector plasmid pKH-GFPpUbi-EmeGFP for fusion protein expression was based on pHR-SIN backbone [75]. The Fc region used in the constructs is derived from locus AJ294730. The scFv78 or Fc-fusion cDNA was cloned into sites of lentiviral vector plasmid as MluI-NotI PCR fragments to replace the GFP fragment and to generate pKH-scFv78, 78Fc, $78 \mathrm{~F}(\mathrm{ab})_{2}$, $78 \mathrm{CH} 2$, and $78 \mathrm{mb}$ respectively. The corresponding lentivirus was generated by calcium phosphate-mediated transient transfection of the antibody constructs together with the plasmids encoding the vesicular stomatitis virus $\mathrm{G}$ envelope gag-pol genes and pHRSIN-TEM1 into HEK$293 \mathrm{~T}$ cells. Conditioned media containing virus were harvested 24 and 48 hours post-transfection, filtered with 
$0.45 \mu \mathrm{m}$ filters, and frozen at $-80{ }^{\circ} \mathrm{C}$ for further use.

\section{Cell lines}

MILE SVEN 1 (ATCC) mouse endothelial cell line engineered to express DsRed and firefly luciferase, denoted MS1, has been described previously [35, 36]. MS1 was used for subsequent generation of the MS1TEM1 cell line that expresses human TEM1 (hTEM1) and EmGFP, in addition to DsRed and fLuc $[35,36]$. 2H11 murine endothelial cell line was used as muTEM1positive control (ATCC). TC1, a C57BL/6 mouse lung adenocarcinoma cell line transformed with HPV-16 E6 and E7, was a generous gift from Dr Yvonne Patterson (University of Pennsylvania). The TC1 cell line engineered to express firefly luciferase fLuc, denoted TC1, was used in this study. MS1, MS1-TEM1, 2H11 and TC1 cells were cultured in RPMI1640 medium (Corning Cellgro, USA) containing 10\% fetal bovine serum (FBS), $100 \mathrm{I} . \mathrm{U} / \mathrm{mL}$ penicillin, and $100 \mu \mathrm{g} / \mathrm{mL}$ streptomycin. Cells were incubated at $37^{\circ} \mathrm{C}$ in a humidified atmosphere of 5 $\% \mathrm{CO}_{2} .293-\mathrm{F}$ cells were cultured in Gibco ${ }^{\circledR}$ FreeStyle ${ }^{\mathrm{TM}}$ 293 Expression Medium (Invitrogen) in a shaker flask and incubated in a $37^{\circ} \mathrm{C}$ incubator containing a humidified atmosphere of $8 \% \mathrm{CO}_{2}$ in air on an orbital shaker platform rotating at $125 \mathrm{rpm}$.

\section{Transfection and protein purification}

Transfection of FreeStyle ${ }^{\mathrm{TM}} 293$ cells was done according to the manufacturer's instruction. The culture supernatants were harvested at $72 \mathrm{~h}$ post transfection and filtered through $0.45 \mu \mathrm{m}$ filter unit before purification. The supernatants were concentrated with 10k MWCO centrifugal filters (Millipore) and dialyzed with PBS before further purification. Small-scale protein purification was performed according to the manufacturer's protocol for anti-HA affinity matrix (Roche). Briefly, samples were incubated with Anti-HA affinity matrix and following three washes, specifically-bound proteins were eluted by HA peptide (Roche) in elution buffer and then dialyzed with PBS three times. The purity of each protein was analyzed using coomassie blue staining, Silverquest staining (Invitrogen) and SEC analysis.

\section{Codon optimization and scale up production and purification}

The codon usage was analyzed with GeneOptimizer ${ }^{\circledR}$ (Life Technologies) and adapted to the codon bias of Homo sapiens genes. In addition, regions of very high $(>80 \%)$ or very low $(<30 \%)$ GC content were avoided where possible. During the optimization process, the following cis-acting sequence motifs were avoided: internal TATA-boxes, chi-sites and ribosomal entry sites; AT-rich or GC-rich sequence stretches; RNA instability motifs; repeat sequences and RNA secondary structures; splice donor and acceptor sites in higher eukaryotes. Post optimization, GC content was adjusted to prolong mRNA half-life [76]. Codon usage was adapted to the bias of Homo sapiens resulting in a CAI (codon adaptation index) value of 0.96 .

Scale up protein production was done using the codon-optimized sequence in the pcDNA3.3 vector according to the manufacturer's protocols (Invitrogen). In brief, 6 days post-transfection, the supernatant was concentrated by tangential flow filtration before being applied onto anti-HA agarose or HiTrap Protein G HP for affinity enrichment. The binding buffer was $20 \mathrm{mM}$ sodium phosphate and the elution buffer was $0.1 \mathrm{M}$ Glycine (pH 2.4). All collection tubes contained 20\% 1 $\mathrm{M}$ Tris- $\mathrm{HCl}(\mathrm{pH} 8.0)$ to neutralize the eluate fractions. Enriched protein was further purified by SEC on a Sephacryl S200 column pre-equilibrated with PBS (pH 7.5). Fractions containing the purified protein were pooled and dialyzed for $16 \mathrm{~h}$ against $\mathrm{PBS}(\mathrm{pH} 7.5)$ before adjustment to $1 \mathrm{mg} / \mathrm{mL}$. Aliquots were stored at $-80^{\circ} \mathrm{C}$. Purity was determined as described above. Yield (mg/ Liter culture) was quantified by spectrophotometry with a Nanodrop 2000 instrument (Thermo Scientific) and coomassie staining alongside a known loading of BSA.

\section{Western blot analysis and multivalent status assay of the antibody variants}

Proteins were separated according to their molecular weight on 4-15\% Mini-protean TGX precast gels (BioRad) and transferred onto Immobilon-P transfer membrane (Millipore). Membranes were blocked for $1 \mathrm{~h}$ in $5 \%$ dried milk in TBST at room temperature and probed overnight at $4{ }^{\circ} \mathrm{C}$ with rotation in primary antibody anti-HA-HRP (Abcam, 1:5000 dilute). After 3 washes, the bands were visualized using a chemiluminescent substrate (GE Healthcare).

\section{SEC analysis of purified fusion proteins}

Recombinant antibody reagents including $78 \mathrm{Fc}$, $78 \mathrm{~F}\left(\mathrm{ab}^{\prime}\right) 2,78 \mathrm{CH} 2,78 \mathrm{mb}$, and scFv78 were analyzed via a Superdex 200 10/300 gel-filtration column (GE

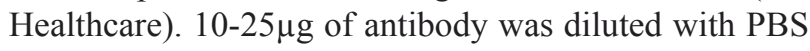
to a final volume of $250 \mu \mathrm{L}$. The samples were spanned at $20,000 \mathrm{~g}$ for $5 \mathrm{~min}$ before injection. The sample was applied via a $500 \mu \mathrm{L}$ loop at a flow rate of $0.5 \mathrm{~mL} / \mathrm{min}$ using an AKTA FPLC system (GE Healthcare). The eluting protein was detected by UV absorbance at 280 $\mathrm{nm}$ and the elution volumes were recorded for analysis. Column calibration with appropriate MW standards (BioRad) was performed prior to and following each run in 
order to allow the estimation of antibody reagent MWs. Peak fractions were collected using the AKTA FPLC Frac950 collector for further analysis.

\section{Radiolabeling and Immunoreactivity assays}

Purified fusion proteins $(50 \mu \mathrm{g})$ were radio-iodinated with $\sim 18.5 \mathrm{MBq}(0.5 \mathrm{mCi})$ of ${ }^{125} \mathrm{I}-\mathrm{NaI}$ (Perkin Elmer) in $0.01 \mathrm{~N} \mathrm{NaOH}$ for 5 min using pre-coated iodination tubes (Thermo Scientific) as previously described [35]. Radiolabeled antibody was purified over a $2 \mathrm{~mL}$ desalting column (Thermo Scientific). Following trichloroacetic acid precipitation, radiolabeling efficiency was determined by radio-TLC.

Immunoreactivity was assayed as previously described [35]. Briefly, radio-iodinated proteins (5 nM $-0.016 \mathrm{nM}$ ) were incubated with an excess of MS1TEM1 cells for $1 \mathrm{~h}$. The mixture was centrifuged, and the activity remaining in the supernatant was counted. A more sensitive assessment of specific binding was done by live-cell radioimmunoassay (RIA). Cells were grown to confluence on 1\% gelatin-coated 96-strip well microplates (Corning Life Sciences). For the binding assay, monolayers of cells were incubated with increasing concentrations of ${ }^{125} \mathrm{I}$-labeled proteins in assay buffer $(5 \%$ FBS in RPMI 1040) in quadruplicate at $4{ }^{\circ} \mathrm{C}$ for $4 \mathrm{~h}$. At the end of incubation, cells were washed five times with ice-cold wash buffer (3\% BSA/PBS). The cell-associated radioactivity was measured by a gamma $(\gamma)$ counter (Wizard 2470, Perkin Elmer) and was normalized to the total number of cells, as counted by a hemocytometer. Non-specific binding (NSB) was calculated by subtracting the radiolabel bound to control MS1 cells from the total binding. The data from the live-cell RIA experiments were analyzed by Scatchard analysis using Prism 5.0 (GraphPad) software to determine equilibrium binding constants and the number of functional binding sites. The apparent binding affinity, $\mathrm{K}_{\mathrm{d}}$, for specific binding was calculated using non-linear regression analysis of a onesite binding hyperbola equation. $\mathrm{B}_{\max }$ is the maximum number of binding sites per cell at the asymptotic maximum; $\mathrm{K}_{\mathrm{d}}$ and $\mathrm{B}_{\max }$ values are presented as the mean $\pm \mathrm{SD}$ of three or more independent experiments, and each independent experiment was performed in quadruplicate.

\section{Blood pharmacokinetics (PK) and biodistribution studies}

Naïve mice were administered ${ }^{125} \mathrm{I}$-labeled protein $(0.185 \mathrm{MBq}$ [ $5 \mu \mathrm{Ci}$ ], $5 \mu \mathrm{g}$ of protein, in $150 \mu \mathrm{L}$ of saline) via the tail vein $(0 \mathrm{~h})$. Blood samples were collected at designated time points by retro-orbital bleed for assessment of blood activity levels. Blood activity levels were fitted to bi-exponential decay curves, and decay constants were calculated. Animals ( $n=3-6$ per group) were euthanized at $1,2,4,24,48,72$, and $144 \mathrm{~h}$ after injection. Organs and tumors were harvested and weighed, and the accumulated radioactivity was counted in a gamma counter.

\section{Live-cell ELISA-based direct binding assay}

96-well plates were coated with $50 \mu \mathrm{L} 2 \%$ gelatin (Sigma) at $37^{\circ} \mathrm{C}$ for $30 \mathrm{~min}$. After discarding the gelatin, plates were washed with $200 \mu \mathrm{L}$ PBS. MS1 and MS1TEM1 cells were seeded in plates $\left(2 \times 10^{4}\right.$ cells per well $)$ and grown at $37^{\circ} \mathrm{C}$ overnight. Cells were incubated with 11 doses (starting from $100 \mathrm{nM}, 3 \times$ serial dilution) of antibody reagents in cell culture media at $4{ }^{\circ} \mathrm{C}$ for 2 h. Plates were washed 3 times with $200 \mu \mathrm{L}$ PBS and incubated with secondary antibody in cell culture media at $4^{\circ} \mathrm{C}$ for $1 \mathrm{~h}$. For scFv78 fusion proteins, the secondary antibody was HA-HRP (Abcam, 1:1500 dilutions), for Biotinylated MORAb004, the secondary antibody was SA-HRP (Abcam, 1:1000 dilutions). Plates were washed with $200 \mu \mathrm{L}$ PBS three times and then developed with 100 $\mu \mathrm{L}$ Sureblue TMB microwell peroxidase substrate (KPL) for $10 \mathrm{~min}$. $100 \mu \mathrm{TMB}$ stop solution (KPL) was added to each well and the A450 was measured in a plate reader (BioTek EL800). ELISA binding curves were analyzed using Prism5.0 (GraphPad) software to determine relative binding affinity constants $\left(\mathrm{IC}_{50}\right)$. Data were fitted using the "non-linear four-parameter logistic sigmoidal doseresponse model". The $\mathrm{K}_{\mathrm{d}}$ value was then calculated from the $\mathrm{IC}_{50}$ value according to Cheng-Prusoff method [77]. $\mathrm{K}_{\mathrm{d}}$ values are reported as the mean \pm standard deviation (SD) of three independent experiments, and each experiment was performed in triplicate.

\section{Serum stability in vitro}

$500 \mathrm{ng}$ of purified proteins $(78 \mathrm{Fc}, \mathrm{scFv} 78,78 \mathrm{CH} 2$, $78 \mathrm{mb}$, or $78 \mathrm{~F}\left(\mathrm{ab}^{\prime}\right)_{2}$ ) were added to $250 \mu \mathrm{L}$ of $100 \%$ human serum and incubated at $37^{\circ} \mathrm{C}$ with shaking. An aliquot (25 $\mu \mathrm{L}, 100 \mathrm{ng}$ protein) of the mixture was taken out at each time point (4h, 24h, 48h, 72h, 96h, 7d) and diluted to $800 \mu \mathrm{L}$ with $\mathrm{PBS}$, and the HA-tagged protein was captured using the HA Tag IP/Co-IP Kit (Pierce). Briefly, each sample was loaded onto the column followed by the addition of $20 \mu \mathrm{L}$ of anti-HA agarose. Columns were incubated with gentle end-over-end mixing for $2 \mathrm{~h}$ at $4{ }^{\circ} \mathrm{C}$, then washed 3 times with $0.5 \mathrm{~mL}$ PBST and added to 25 $\mu \mathrm{L}$ of $2 \times$ Non-Reducing Sample Buffer. The spin column/ tube assembly was heated at $100^{\circ} \mathrm{C}$ on a heating block for 5 minutes and centrifuged for 10 seconds. The collected samples were electrophoresed in a 4-15\% Mini-protean TGX precast gel (Bio-Rad) followed by blotting and western analysis. 


\section{Thermostability assay}

Thermofluor assays were performed to assess the thermal stabilities of purified proteins. The reaction mix contained $5 \mu \mathrm{L}$ of $30 \mathrm{x}$ SYPRO ${ }^{\circledR}$ Orange dye (Invitrogen) and $45 \mu \mathrm{L}$ of sample at $0.11 \mathrm{mg} / \mathrm{mL}$ in PBS pH 7.4. 10 $\mu \mathrm{L}$ of the mix was dispensed in quadruplicate into a 384well PCR optical plate and was analyzed on a 7900HT real-time PCR System (Applied Biosystems) with a ramp rate of $0.5^{\circ} \mathrm{C} / \mathrm{min}$ between $20^{\circ} \mathrm{C}$ and $99^{\circ} \mathrm{C}$. Fluorescence changes in each well were measured, intensity increases plotted, and the inflection point of the slopes was used to calculate the thermostability $\left(\mathrm{T}_{\mathrm{m}}\right)$.

\section{RNA isolation and qRT-PCR}

Total RNA was isolated from 50-100 mg of frozen organs or tumors with TRIzol reagent (Invitrogen). After treatment with RNase-free DNase (Invitrogen), RNA was reprecipitated, quantified by spectrophotometry and analyzed for RNA integrity by BioAnalyzer (Agilent). Total RNA was reverse transcribed using the Superscript First-Strand Synthesis Kit (Invitrogen) for RT-PCR under conditions described by the supplier. Quantitative RTPCR was performed with inventoried mouse or human tem1 probe (Applied Biosystems) with $18 \mathrm{~S}$ probe as endogenous control. The expression of tem 1 in normal organs was normalized using mouse liver or cervix as a calibrator. MS1, TC1 or $2 \mathrm{H} 11$ cell lysates were harvested and total mRNA extracted using Trizol, followed by DNaseI treatment and cDNA generation. Relative gene expression was calculated by the comparative CT method $\left(2^{-\Delta \Delta C T}\right.$ method). Error bars denote standard deviation $(n=3)$ or as indicated.

\section{Conjugation of $78 \mathrm{Fc}$ with Vivotag750}

Conjugation of $78 \mathrm{Fc}$ or control human IgG (Genscript) with VivoTag-S 750 and VivoTag-S 750MAL (Perkin Elmer) was performed according to the manufacturer's instructions. Briefly, $1 \mathrm{~mL}$ of a 1 $\mathrm{mg} / \mathrm{mL}$ antibody solution in conjugation buffer $(50 \mathrm{mM}$ carbonate/bicarbonate buffer, $\mathrm{pH} 8.5$ ) was mixed with $30 \mu \mathrm{L}$ of VivoTag-S 750 at a concentration of $10 \mathrm{mg} / \mathrm{mL}$ in Dimethylsulfoxide (Sigma) and then incubated at room temperature for $1 \mathrm{~h}$. After dialysis in $1 \times \mathrm{PBS}$, the reaction mixture was filtered through a $0.2 \mu \mathrm{m}$ syringe filter. Aliquots of labeled protein were stored at $4{ }^{\circ} \mathrm{C}$ in the dark until ready to analyze.

\section{Murine TEM1-expressing models of TC1}

Subcutaneous (s.c.) tumors with upregulated expression of endogenous murine TEM1 were established by s.c. injection of $4 \times 10^{4} \mathrm{TC} 1$ cells into the right flank of nude mice. All animal experiments were conducted in compliance with Institutional Animal Care and Use Committee guidelines. Female athymic $n u / n u$ mice (strain $088 \mathrm{Nude}^{-/}, 18$ g, 4-6 weeks, Charles River Laboratories) were acclimatized at the Small Animal Imaging Facility (SAIF) vivarium for 1 week before tumors were implanted. Mice were provided with food and water ad libitum. These TC1 cells express firefly luciferase, enabling BLI imaging. Following resections at indicated time points, excised organs and tumors were analyzed for muTEM1 mRNA by quantitative RT-PCR. These mice will develop TC1induced s.c. tumors of approximately $5 \times 5 \mathrm{~mm}$ within 10 days of cell inoculation and succumb in 5-6 weeks. At day 10 after cell inoculation, $78 \mathrm{Fc} 750$ tracer $(5 \mathrm{mg} / \mathrm{kg})$ was injected intravenously $(\mathrm{n}=5)$ for longitudinal $2 \mathrm{D}$ planar NIR and BLI optical imaging.

Lung metastasis tumors were established by intravenous injection of $1 \times 10^{5}$ luciferase expressing TC1 cells. These mice will grow BLI visible lung tumors within 7 days after cell inoculation and succumb in 3-4 weeks. Following resections at 2 wks post injection, excised lung and control organs were analyzed for muTEM1 mRNA by quantitative RT-PCR. At day $14,78 \mathrm{Fc} 750$ tracer $(5 \mathrm{mg} /$ $\mathrm{kg}$ ) was injected intravenously $(\mathrm{n}=5)$ for longitudinal $2 \mathrm{D}$ planar NIR and BLI optical imaging.

\section{Human TEM1-expressing tumor vascular model}

Subcutaneous (s.c.) tumor vascular grafts expressing hTEM1 were established by s.c. injection of $2 \times 10^{7}$ MS1-TEM1 or MS1 in each flank (for 2D study) or on the back for 3D tomography studies (upper: MS1; lower MS1-TEM1). Full details of the model has been described previously [36]. At day $14,78 \mathrm{Fc} 750$ tracer (5 $\mathrm{mg} / \mathrm{kg}$ ) or control IgG-750 were injected intravenously for longitudinal 2D planar NIR and BLI optical imaging $(n=3$ per group). Mice bearing MS1-TEM1 and MS1 tumors on the back were suitable for studies using transillumination light sources and could therefore be used with dual modality tomography (DLIT and FLIT) $(n=5)$.

\section{In vivo 2D planar Bioluminescence Imaging (BLI) and Diffuse Light Imaging Tomography (DLIT)}

Mice bearing engrafts expressing fLuc reporter (MS1 or TC1 cells) were anesthetized with 1-2\% isoflurane $/ \mathrm{O}_{2}$ and BLI was performed using the IVIS Spectrum small animal imaging system (Caliper). Briefly, D-Luciferin (150 mg/mL, Gold Biotechnology) was injected intraperitoneally and optical images were acquired 15 min post-injection. Images were quantified with Living Image Version 3.0 software (Caliper). Quantitative bioluminescence imaging was performed as described elsewhere [78]. The mice bearing MS1-huTEM1 and MS1 
tumors on the back underwent 3D DLIT at day 14 post engraftment $(n=3)$. A structured light image was acquired and followed by a sequential series of images using 20 $\mathrm{nm}$-wide filters centered on wavelengths from 560 to $660 \mathrm{~nm}$. Three-dimensional DLIT takes into account the source emission spectrum as well as the scattering and absorption of light in tissues and can thereby calculate the 3D location and brightness of the luminescent source [79].

\section{In vivo 2D planar NIR fluorescent Imaging and Fluorescence Imaging Tomography (FLIT)}

Mice engrafted with MS1 or TC1 were also imaged with the Pearl Impulse small animal imager (LI-COR), an NIR imaging system designed for use with $700 \mathrm{~nm}$ and $800 \mathrm{~nm}$ wavelengths. This system was used to measure the $78 \mathrm{Fc} 750$ signal at $800 \mathrm{~nm}$ in the longitudinal study after antibody-dye conjugate injections (1 min up to 10 days post injection). Post mortem images were taken to visualize the organ distribution of the labeled antibody.

In addition, the mice bearing MS1-huTEM1 and MS1 tumors on the back underwent FLIT to determine geometry and to quantify the depth and intensity of fluorescent sources in 3D space $(n=5)$. First we obtained a structured light image to reconstruct the surface topography and then fluorescent images (Ex: 745nm; Em: $800 \mathrm{~nm}$ ) were obtained using multiple transillumination points and the same excitation and emission for tomographic mapping of source locations. Voxels were chosen for visualization. A generic mouse organ atlas was used to overlay the surface/source reconstruction, which allows the surface shape of the liver to be displayed. The liver voxels were later confirmed by post mortem $2 \mathrm{D}$ planar NIR of organs.

\section{In vivo Dual Modality Tomography (DLIT with FLIT)}

The tomography source reconstruction and analyses were performed strictly according to the manufacturer's instruction (Perkin Elmer). The mice bearing MS1huTEM1 and MS1 tumors on the back underwent, sequentially, FLIT followed by DLIT while maintaining their physical location/position on the imaging platform. The identical surface topographies from DLIT and FLIT enabled us to combine voxels from FLIT or DLIT for reconstructions. Such operations make it possible to directly visualize in vivo the co-localization of tumor cells (DLIT) with the 78Fc750 tracer (FLIT). Following resections, excised organs were placed in tissue cassettes and imaged under 2D planar NIR.

\section{Statistical analysis}

Unpaired student's t-test or two-way ANOVA statistical analyses were carried out using the SPSS and StatView software packages. A value of $p<0.05$ was considered statistically significant.

\section{ACKNOWLEDGEMENTS}

This work was supported by NIH transformative R01CA156695; Basser Research Center for BRCA1/2, and the Honorable Tina Brozman Foundation (GC). CL is also supported in part by grant \#IRG-78-002-35 from the American Cancer Society, Sandy Rollman Ovarian Cancer Foundation, and SPORE in Ovarian Cancer Pilot Award P50 CA083638-14, NIH. We are thankful to Edward J. Delikatny, Steven H Seeholzer, Catharine Hou, Julie Czupryna and Hua Ding for technical assistance.

\section{AUTHOR CONTRIBUTIONS}

C.L. designed and performed experiments and analyzed data. J.W. J.H., A.M.C., X.P., X.M. and J.L.M. performed experiments. G.C. designed the experiments, supervised the work and edited manuscript. Y.F., C.L. and. S.D. analyzed data and wrote the paper. K.H., A.Z., V.R.M. and D.A.P. contributed reagents or analytical tools.

\section{REFERENCES}

1. Ahmad ZA, Yeap SK, Ali AM, Ho WY, Alitheen NB and Hamid M. scFv antibody: principles and clinical application. Clin Dev Immunol. 2012; 2012:980250.

2. van Dongen GA, Visser GW, Lub-de Hooge MN, de Vries EG and Perk LR. Immuno-PET: a navigator in monoclonal antibody development and applications. Oncologist. 2007; 12(12):1379-1389.

3. Stuker F, Ripoll J and Rudin M. Fluorescence molecular tomography: principles and potential for pharmaceutical research. Pharmaceutics. 2011; 3(2):229-274.

4. Intes X, Ripoll J, Chen Y, Nioka S, Yodh AG and Chance B. In vivo continuous-wave optical breast imaging enhanced with Indocyanine Green. Med Phys. 2003; 30(6):10391047.

5. Tanaka E, Choi HS, Fujii H, Bawendi MG and Frangioni JV. Image-guided oncologic surgery using invisible light: completed pre-clinical development for sentinel lymph node mapping. Ann Surg Oncol. 2006; 13(12):1671-1681.

6. Kim S, Lim YT, Soltesz EG, De Grand AM, Lee J, Nakayama A, Parker JA, Mihaljevic T, Laurence RG, Dor DM, Cohn LH, Bawendi MG and Frangioni JV. Nearinfrared fluorescent type II quantum dots for sentinel lymph node mapping. Nat Biotechnol. 2004; 22(1):93-97.

7. Soltesz EG, Kim S, Laurence RG, DeGrand AM, Parungo 
CP, Dor DM, Cohn LH, Bawendi MG, Frangioni JV and Mihaljevic T. Intraoperative sentinel lymph node mapping of the lung using near-infrared fluorescent quantum dots. The Annals of thoracic surgery. 2005; 79(1):269-277; discussion 269-277.

8. Ohnishi S, Lomnes SJ, Laurence RG, Gogbashian A, Mariani $G$ and Frangioni JV. Organic alternatives to quantum dots for intraoperative near-infrared fluorescent sentinel lymph node mapping. Mol Imaging. 2005; 4(3):172-181.

9. Parungo CP, Ohnishi S, Kim SW, Kim S, Laurence RG, Soltesz EG, Chen FY, Colson YL, Cohn LH, Bawendi MG and Frangioni JV. Intraoperative identification of esophageal sentinel lymph nodes with near-infrared fluorescence imaging. J Thorac Cardiovasc Surg. 2005; 129(4):844-850.

10. Parker BS, Argani P, Cook BP, Liangfeng H, Chartrand SD, Zhang M, Saha S, Bardelli A, Jiang Y, St Martin TB, Nacht M, Teicher BA, Klinger KW, Sukumar S and Madden SL. Alterations in vascular gene expression in invasive breast carcinoma. Cancer research. 2004; 64(21):7857-7866.

11. Lu C, Bonome T, Li Y, Kamat AA, Han LY, Schmandt R, Coleman RL, Gershenson DM, Jaffe RB, Birrer MJ and Sood AK. Gene alterations identified by expression profiling in tumor-associated endothelial cells from invasive ovarian carcinoma. Cancer research. 2007; 67(4):17571768.

12. Buckanovich RJ, Sasaroli D, O’Brien-Jenkins A, Botbyl J, Hammond R, Katsaros D, Sandaltzopoulos R, Liotta LA, Gimotty PA and Coukos G. Tumor vascular proteins as biomarkers in ovarian cancer. J Clin Oncol. 2007; 25(7):852-861

13. St Croix B, Rago C, Velculescu V, Traverso G, Romans KE, Montgomery E, Lal A, Riggins GJ, Lengauer C, Vogelstein B and Kinzler KW. Genes expressed in human tumor endothelium. Science. 2000; 289(5482):1197-1202.

14. Bhati R, Patterson C, Livasy CA, Fan C, Ketelsen D, Hu Z, Reynolds E, Tanner C, Moore DT, Gabrielli F, Perou $\mathrm{CM}$ and Klauber-DeMore N. Molecular characterization of human breast tumor vascular cells. The American journal of pathology. 2008; 172(5):1381-1390.

15. Madden SL, Cook BP, Nacht M, Weber WD, Callahan MR, Jiang Y, Dufault MR, Zhang X, Zhang W, WalterYohrling J, Rouleau C, Akmaev VR, Wang CJ, Cao X, St Martin TB, Roberts BL, et al. Vascular gene expression in nonneoplastic and malignant brain. The American journal of pathology. 2004; 165(2):601-608.

16. Ulahannan SV and Brahmer JR. Antiangiogenic agents in combination with chemotherapy in patients with advanced non-small cell lung cancer. Cancer Invest. 2011; 29(4):325337.

17. Mulder K, Scarfe A, Chua N and Spratlin J. The role of bevacizumab in colorectal cancer: understanding its benefits and limitations. Expert Opin Biol Ther. 2011; 11(3):405413.
18. Ebos JM and Kerbel RS. Antiangiogenic therapy: impact on invasion, disease progression, and metastasis. Nat Rev Clin Oncol. 2011; 8(4):210-221.

19. von Minckwitz G, Eidtmann H, Rezai M, Fasching PA, Tesch H, Eggemann H, Schrader I, Kittel K, Hanusch C, Kreienberg R, Solbach C, Gerber B, Jackisch C, Kunz G, Blohmer JU, Huober J, et al. Neoadjuvant chemotherapy and bevacizumab for HER2-negative breast cancer. The New England journal of medicine. 2012; 366(4):299-309.

20. Christian S, Ahorn H, Koehler A, Eisenhaber F, Rodi HP, Garin-Chesa P, Park JE, Rettig WJ and Lenter MC. Molecular cloning and characterization of endosialin, a C-type lectin-like cell surface receptor of tumor endothelium. J Biol Chem. 2001; 276(10):7408-7414.

21. Rettig WJ, Garin-Chesa P, Healey JH, Su SL, Jaffe EA and Old LJ. Identification of endosialin, a cell surface glycoprotein of vascular endothelial cells in human cancer. Proc Natl Acad Sci U S A. 1992; 89(22):10832-10836.

22. Becker R, Lenter MC, Vollkommer T, Boos AM, Pfaff D, Augustin HG and Christian S. Tumor stroma marker endosialin (Tem1) is a binding partner of metastasis-related protein Mac-2 BP/90K. FASEB J. 2008; 22(8):3059-3067.

23. Tomkowicz B, Rybinski K, Foley B, Ebel W, Kline B, Routhier E, Sass P, Nicolaides NC, Grasso L and Zhou Y. Interaction of endosialin/TEM1 with extracellular matrix proteins mediates cell adhesion and migration. Proc Natl Acad Sci U S A. 2007; 104(46):17965-17970.

24. Christian S, Winkler R, Helfrich I, Boos AM, Besemfelder E, Schadendorf D and Augustin HG. Endosialin (Tem1) is a marker of tumor-associated myofibroblasts and tumor vessel-associated mural cells. Am J Pathol. 2008; 172(2):486-494.

25. Davies G, Cunnick GH, Mansel RE, Mason MD and Jiang WG. Levels of expression of endothelial markers specific to tumour-associated endothelial cells and their correlation with prognosis in patients with breast cancer. Clin Exp Metastasis. 2004; 21(1):31-37.

26. Conejo-Garcia JR, Buckanovich RJ, Benencia F, Courreges MC, Rubin SC, Carroll RG and Coukos G. Vascular leukocytes contribute to tumor vascularization. Blood. 2005; 105(2):679-681.

27. Brady J, Neal J, Sadakar N and Gasque P. Human endosialin (tumor endothelial marker 1) is abundantly expressed in highly malignant and invasive brain tumors. J Neuropathol Exp Neurol. 2004; 63(12):1274-1283.

28. Buckanovich RJ, Sasaroli D, O’Brien-Jenkins A, Botbyl J, Conejo-Garcia JR, Benencia F, Liotta LA, Gimotty PA and Coukos G. Use of Immuno-LCM to Identify the in situ Expression Profile of Cellular Constituents of the Tumor Microenvironment. Cancer biology \& therapy. 2006; 5(6):635-642.

29. Neri D and Bicknell R. Tumour vascular targeting. Nat Rev Cancer. 2005; 5(6):436-446.

30. Carson-Walter EB, Watkins DN, Nanda A, Vogelstein B, 
Kinzler KW and St Croix B. Cell surface tumor endothelial markers are conserved in mice and humans. Cancer Res. 2001; 61(18):6649-6655.

31. Walter-Yohrling J, Morgenbesser S, Rouleau C, Bagley R, Callahan M, Weber W and Teicher BA. Murine endothelial cell lines as models of tumor endothelial cells. Clin Cancer Res. 2004; 10(6):2179-2189.

32. Nanda A, Karim B, Peng Z, Liu G, Qiu W, Gan C, Vogelstein B, St Croix B, Kinzler KW and Huso DL. Tumor endothelial marker 1 (Tem1) functions in the growth and progression of abdominal tumors. Proceedings of the National Academy of Sciences of the United States of America. 2006; 103(9):3351-3356.

33. Rouleau C, Sancho J, Campos-Rivera J and Teicher BA. Endosialin expression in side populations in human sarcoma cell lines. Oncol Lett. 2012; 3(2):325-329.

34. Rouleau C, Curiel M, Weber W, Smale R, Kurtzberg L, Mascarello J, Berger C, Wallar G, Bagley R, Honma N, Hasegawa K, Ishida I, Kataoka S, Thurberg BL, Mehraein $\mathrm{K}$, Horten B, et al. Endosialin protein expression and therapeutic target potential in human solid tumors: sarcoma versus carcinoma. Clinical cancer research : an official journal of the American Association for Cancer Research. 2008; 14(22):7223-7236.

35. Chacko* A-M, Li* C, Nayak M, Mikitsh JL, Hu J, Hou C, Grasso L, Nicolaides NC, Muzykantov VR, Divgi CR and Coukos G. Development of 124I-Immuno-PET Targeting Tumor Vascular TEM1/Endosialin. J Nucl Med 2014; 55:18.

36. Li C, Chacko A-M, Hu J, Hasegawa K, Swails J, Grasso L, El-Deiry WS, Nicolaides N, Muzykantov V, Divgi CR and Coukos G. Antibody-based tumor vascular theranostics targeting endosialin/TEM1 in a new mouse tumor vascular model. cancer Biol Ther. 2014; 15(4).

37. Zhao A, Nunez-Cruz S, Li C, Coukos G, Siegel DL and Scholler N. Rapid isolation of high-affinity human antibodies against the tumor vascular marker Endosialin/ TEM1, using a paired yeast-display/secretory scFv library platform. J Immunol Methods. 2011; 363(2):221-232.

38. Kontermann RE. Strategies for extended serum halflife of protein therapeutics. Curr Opin Biotechnol. 2011; 22(6):868-876.

39. Carter PJ. Introduction to current and future protein therapeutics: a protein engineering perspective. Experimental cell research. 2011; 317(9):1261-1269.

40. Czajkowsky DM, Hu J, Shao Z and Pleass RJ. Fc-fusion proteins: new developments and future perspectives. EMBO Mol Med. 2012; 4(10):1015-1028.

41. Shen BQ, Xu K, Liu L, Raab H, Bhakta S, Kenrick M, Parsons-Reponte KL, Tien J, Yu SF, Mai E, Li D, Tibbitts J, Baudys J, Saad OM, Scales SJ, McDonald PJ, et al. Conjugation site modulates the in vivo stability and therapeutic activity of antibody-drug conjugates. Nat Biotechnol. 2012; 30(2):184-189.
42. Agarwal A, Mackey MA, El-Sayed MA and Bellamkonda $\mathrm{RV}$. Remote triggered release of doxorubicin in tumors by synergistic application of thermosensitive liposomes and gold nanorods. ACS Nano. 2011; 5(6):4919-4926.

43. Reiner T, Thurber G, Gaglia J, Vinegoni C, Liew CW, Upadhyay R, Kohler RH, Li L, Kulkarni RN, Benoist C, Mathis D and Weissleder R. Accurate measurement of pancreatic islet beta-cell mass using a second-generation fluorescent exendin-4 analog. Proceedings of the National Academy of Sciences of the United States of America. 2011; 108(31):12815-12820.

44. Borjesson PK, Jauw YW, Boellaard R, de Bree R, Comans EF, Roos JC, Castelijns JA, Vosjan MJ, Kummer JA, Leemans CR, Lammertsma AA and van Dongen GA. Performance of immuno-positron emission tomography with zirconium-89-labeled chimeric monoclonal antibody U36 in the detection of lymph node metastases in head and neck cancer patients. Clinical cancer research : an official journal of the American Association for Cancer Research. 2006; 12(7 Pt 1):2133-2140.

45. Perk LR, Stigter-van Walsum M, Visser GW, Kloet RW, Vosjan MJ, Leemans CR, Giaccone G, Albano R, Comoglio PM and van Dongen GA. Quantitative PET imaging of Metexpressing human cancer xenografts with 89Zr-labelled monoclonal antibody DN30. Eur J Nucl Med Mol Imaging. 2008; 35(10):1857-1867.

46. Brouwers A, Verel I, Van Eerd J, Visser G, Steffens M, Oosterwijk E, Corstens F, Oyen W, Van Dongen G and Boerman O. PET radioimmunoscintigraphy of renal cell cancer using 89Zr-labeled cG250 monoclonal antibody in nude rats. Cancer Biother Radiopharm. 2004; 19(2):155163.

47. Divgi CR, Pandit-Taskar N, Jungbluth AA, Reuter VE, Gonen M, Ruan S, Pierre C, Nagel A, Pryma DA, Humm J, Larson SM, Old LJ and Russo P. Preoperative characterisation of clear-cell renal carcinoma using iodine124-labelled antibody chimeric G250 (124I-cG250) and PET in patients with renal masses: a phase I trial. Lancet Oncol. 2007; 8(4):304-310.

48. Hoeben BA, Kaanders JH, Franssen GM, Troost EG, Rijken PF, Oosterwijk E, van Dongen GA, Oyen WJ, Boerman OC and Bussink J. PET of hypoxia with 89Zrlabeled cG250-F(ab')2 in head and neck tumors. Journal of nuclear medicine : official publication, Society of Nuclear Medicine. 2010; 51(7):1076-1083.

49. Tijink BM, Perk LR, Budde M, Stigter-van Walsum M, Visser GW, Kloet RW, Dinkelborg LM, Leemans CR, Neri D and van Dongen GA. (124)I-L19-SIP for immuno-PET imaging of tumour vasculature and guidance of (131)I-L19SIP radioimmunotherapy. Eur J Nucl Med Mol Imaging. 2009; 36(8):1235-1244.

50. Heskamp S, van Laarhoven HW, Molkenboer-Kuenen JD, Franssen GM, Versleijen-Jonkers YM, Oyen WJ, van der Graaf WT and Boerman OC. ImmunoSPECT and immunoPET of IGF-1R expression with the radiolabeled 
antibody R1507 in a triple-negative breast cancer model. Journal of nuclear medicine : official publication, Society of Nuclear Medicine. 2010; 51(10):1565-1572.

51. Holland JP, Divilov V, Bander NH, Smith-Jones PM, Larson SM and Lewis JS. 89Zr-DFO-J591 for immunoPET of prostate-specific membrane antigen expression in vivo. Journal of nuclear medicine : official publication, Society of Nuclear Medicine. 2010; 51(8):1293-1300.

52. Ruggiero A, Holland JP, Hudolin T, Shenker L, Koulova A, Bander NH, Lewis JS and Grimm J. Targeting the internal epitope of prostate-specific membrane antigen with 89Zr-7E11 immuno-PET. Journal of nuclear medicine : official publication, Society of Nuclear Medicine. 2011; 52(10):1608-1615.

53. Hong H, Severin GW, Yang Y, Engle JW, Zhang Y, Barnhart TE, Liu G, Leigh BR, Nickles RJ and Cai W. Positron emission tomography imaging of CD105 expression with 89Zr-Df-TRC105. Eur J Nucl Med Mol Imaging. 2012; 39(1):138-148.

54. Perk LR, Visser GW, Vosjan MJ, Stigter-van Walsum M, Tijink BM, Leemans CR and van Dongen GA. (89)Zr as a PET surrogate radioisotope for scouting biodistribution of the therapeutic radiometals $(90) \mathrm{Y}$ and $(177) \mathrm{Lu}$ in tumorbearing nude mice after coupling to the internalizing antibody cetuximab. Journal of nuclear medicine : official publication, Society of Nuclear Medicine. 2005; 46(11):1898-1906.

55. Aerts HJ, Dubois L, Perk L, Vermaelen P, van Dongen GA, Wouters BG and Lambin P. Disparity between in vivo EGFR expression and 89Zr-labeled cetuximab uptake assessed with PET. Journal of nuclear medicine : official publication, Society of Nuclear Medicine. 2009; 50(1):123131.

56. Perk LR, Visser OJ, Stigter-van Walsum M, Vosjan MJ, Visser GW, Zijlstra JM, Huijgens PC and van Dongen GA. Preparation and evaluation of (89)Zr-Zevalin for monitoring of (90)Y-Zevalin biodistribution with positron emission tomography. Eur J Nucl Med Mol Imaging. 2006; 33(11):1337-1345.

57. Tran L, Huitema AD, van Rijswijk MH, Dinant HJ, Baars JW, Beijnen JH and Vogel WV. CD20 antigen imaging with (1)(2)(4)I-rituximab PET/CT in patients with rheumatoid arthritis. Hum Antibodies. 2011; 20(1-2):29-35.

58. Nagengast WB, de Vries EG, Hospers GA, Mulder NH, de Jong JR, Hollema H, Brouwers AH, van Dongen GA, Perk LR and Lub-de Hooge MN. In vivo VEGF imaging with radiolabeled bevacizumab in a human ovarian tumor xenograft. Journal of nuclear medicine : official publication, Society of Nuclear Medicine. 2007; 48(8):1313-1319.

59. Nagengast WB, de Korte MA, Oude Munnink TH, TimmerBosscha H, den Dunnen WF, Hollema H, de Jong JR, Jensen MR, Quadt C, Garcia-Echeverria C, van Dongen GA, Lub-de Hooge MN, Schroder CP and de Vries EG. 89Zr-bevacizumab PET of early antiangiogenic tumor response to treatment with HSP90 inhibitor NVP-AUY922.
Journal of nuclear medicine : official publication, Society of Nuclear Medicine. 2010; 51(5):761-767.

60. Dijkers EC, Kosterink JG, Rademaker AP, Perk LR, van Dongen GA, Bart J, de Jong JR, de Vries EG and Lub-de Hooge MN. Development and characterization of clinicalgrade $89 \mathrm{Zr}$-trastuzumab for HER2/neu immunoPET imaging. Journal of nuclear medicine : official publication, Society of Nuclear Medicine. 2009; 50(6):974-981.

61. Dijkers EC, Oude Munnink TH, Kosterink JG, Brouwers AH, Jager PL, de Jong JR, van Dongen GA, Schroder $\mathrm{CP}$, Lub-de Hooge MN and de Vries EG. Biodistribution of 89Zr-trastuzumab and PET imaging of HER2-positive lesions in patients with metastatic breast cancer. Clin Pharmacol Ther. 2010; 87(5):586-592.

62. Holland JP, Caldas-Lopes E, Divilov V, Longo VA, Taldone T, Zatorska D, Chiosis G and Lewis JS. Measuring the pharmacodynamic effects of a novel Hsp90 inhibitor on HER2/neu expression in mice using Zr-DFO-trastuzumab. PLoS One. 2010; 5(1):e8859.

63. Olafsen T, Betting D, Kenanova VE, Salazar FB, Clarke P, Said J, Raubitschek AA, Timmerman JM and Wu AM. Recombinant anti-CD20 antibody fragments for smallanimal PET imaging of B-cell lymphomas. Journal of nuclear medicine : official publication, Society of Nuclear Medicine. 2009; 50(9):1500-1508.

64. Olafsen T, Sirk SJ, Betting DJ, Kenanova VE, Bauer KB, Ladno W, Raubitschek AA, Timmerman JM and Wu AM. ImmunoPET imaging of B-cell lymphoma using 124I-antiCD20 scFv dimers (diabodies). Protein Eng Des Sel. 2010; 23(4):243-249.

65. Olafsen $\mathrm{T}$ and $\mathrm{Wu}$ AM. Antibody vectors for imaging. Semin Nucl Med. 2010; 40(3):167-181.

66. Kenanova V, Olafsen T, Crow DM, Sundaresan G, Subbarayan M, Carter NH, Ikle DN, Yazaki PJ, Chatziioannou AF, Gambhir SS, Williams LE, Shively JE, Colcher D, Raubitschek AA and Wu AM. Tailoring the pharmacokinetics and positron emission tomography imaging properties of anti-carcinoembryonic antigen singlechain Fv-Fc antibody fragments. Cancer research. 2005; 65(2):622-631.

67. Deng R, Iyer S, Theil FP, Mortensen DL, Fielder PJ and Prabhu S. Projecting human pharmacokinetics of therapeutic antibodies from nonclinical data: what have we learned? MAbs. 2011; 3(1):61-66.

68. Dolznig H, Schweifer N, Puri C, Kraut N, Rettig WJ, Kerjaschki D and Garin-Chesa P. Characterization of cancer stroma markers: in silico analysis of an mRNA expression database for fibroblast activation protein and endosialin. Cancer immunity. 2005; 5:10.

69. Keller E, Nadler A, Alkadhi H, Kollias SS, Yonekawa $\mathrm{Y}$ and Niederer P. Noninvasive measurement of regional cerebral blood flow and regional cerebral blood volume by near-infrared spectroscopy and indocyanine green dye dilution. Neuroimage. 2003; 20(2):828-839. 
70. Brown DW, Picot PA, Naeini JG, Springett R, Delpy DT and Lee TY. Quantitative near infrared spectroscopy measurement of cerebral hemodynamics in newborn piglets. Pediatr Res. 2002; 51(5):564-570.

71. Tichauer KM, Hadway JA, Lee TY and St Lawrence K. Measurement of cerebral oxidative metabolism with nearinfrared spectroscopy: a validation study. J Cereb Blood Flow Metab. 2006; 26(5):722-730.

72. Rao R. Is change in regional (somatic) near-infrared spectroscopy not a useful indictor of clinically detectable low cardiac output in children after surgery for congenital heart defects? Pediatr Crit Care Med. 2013; 14(3):340-341.

73. Bhalala US, Nishisaki A, McQueen D, Bird GL, Morrison WE, Nadkarni VM, Nathan M and Starr JP. Change in regional (somatic) near-infrared spectroscopy is not a useful indicator of clinically detectable low cardiac output in children after surgery for congenital heart defects. Pediatr Crit Care Med. 2012; 13(5):529-534.

74. van Dam GM, Themelis G, Crane LM, Harlaar NJ, Pleijhuis RG, Kelder W, Sarantopoulos A, de Jong JS, Arts HJ, van der Zee AG, Bart J, Low PS and Ntziachristos $\mathrm{V}$. Intraoperative tumor-specific fluorescence imaging in ovarian cancer by folate receptor-alpha targeting: first inhuman results. Nat Med. 2011; 17(10):1315-1319.

75. Hasegawa K, Pham L, O'Connor MK, Federspiel MJ, Russell SJ and Peng KW. Dual therapy of ovarian cancer using measles viruses expressing carcinoembryonic antigen and sodium iodide symporter. Clin Cancer Res. 2006; 12(6):1868-1875.

76. Kudla G, Lipinski L, Caffin F, Helwak A and Zylicz M. High guanine and cytosine content increases mRNA levels in mammalian cells. PLoS Biol. 2006; 4(6):e180.

77. Cheng Y and Prusoff WH. Relationship between the inhibition constant (K1) and the concentration of inhibitor which causes 50 per cent inhibition (I50) of an enzymatic reaction. Biochem Pharmacol. 1973; 22(23):3099-3108.

78. El-Deiry WS, Sigman CC and Kelloff GJ. Imaging and oncologic drug development. J Clin Oncol. 2006; 24(20):3261-3273.

79. Kuo C, Coquoz O, Troy TL, Xu H and Rice BW. Threedimensional reconstruction of in vivo bioluminescent sources based on multispectral imaging. J Biomed Opt. 2007; 12(2):024007. 